\title{
A Model of the Interaction of Health and Healthcare for the Wellbeing of Heterogeneous Individuals
}

\author{
Anita King
}

May 2018

A dissertation presented to

Victoria University of Wellington

in partial fulfilment of the degree of

Master of Commerce 


\section{Abstract}

A model is proposed here to investigate how the relationships between health, production, and wellbeing contribute to the achievement (or otherwise) of potential government objectives. This model uses a basic general equilibrium framework with heterogeneous individuals and two goods (healthcare and other). Public health and publically and privately provided healthcare affect health level, which in turn affects productivity. Several different potential objectives of the government agent are investigated, which determine the distribution of public healthcare. The model is solved numerically to understand the effects of the choices of government objectives including the level of inequality aversion and varying tax rates. For governments with high inequality aversion that maximise social welfare from utility, a non-zero tax rate may be optimal, even with high levels of public health. 


\section{Acknowledgements}

I want to thank my supervisor Arthur Grimes, the New Zealand Treasury for supporting this study, and my husband and children for putting up with me when I was writing this dissertation instead of spending time with them. The views, opinions, findings, conclusions and recommendations expressed in this dissertation are strictly those of the author; and do not necessarily reflect the views of anyone else particularly the New Zealand Treasury. 


\section{Contents}

1 Introduction 1

1.1 Definitions . . . . . . . . . . . . . . . . . . 2

1.2 Externalities . . . . . . . . . . . . . . . . . . . 3

1.3 This Model . . . . . . . . . . . . . . . . . . 3

2 Literature $\quad 6$

2.1 Wellbeing of Individuals and Societies . . . . . . . . . 6

2.1.1 What is Wellbeing? . . . . . . . . . . . 6

2.1.2 GDP and Wellbeing .............. 9

2.1.3 Wellbeing of Individuals . . . . . . . . . . . 11

2.1.4 Wellbeing of Society . . . . . . . . . . . 12

2.2 Objectives of Government Policy . . . . . . . . . . . . . . 14

2.3 Wellbeing Measurement and Modelling . . . . . . . . . . . 18

2.4 Models of Health, Income, and Wellbeing . . . . . . . . . . 22

2.4.1 Grossman model . . . . . . . . . . . . . . . . . 22

2.4.2 Fleurbaey Model . . . . . . . . . . . . 25 
3.1 Individuals . . . . . . . . . . . . . . . . . . . . . . . . . . 29

3.1.1 Definition Equations . . . . . . . . . . . 30

3.1.2 Accounting Equations . . . . . . . . . . . . 32

3.1.3 Behaviour Equations . . . . . . . . . . . . . 33

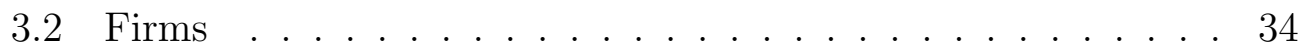

3.2.1 Definition Equations . . . . . . . . . . . . 35

3.2.2 Behaviour Equations . . . . . . . . . . . . 36

3.2.3 Accounting Equations . . . . . . . . . . . . 36

3.3 Government . . . . . . . . . . . . . . . . . 38

3.3.1 Definition Equations . . . . . . . . . . . . . 38

3.3.2 Accounting Equations . . . . . . . . . . . 38

3.3.3 Behaviour Equations . . . . . . . . . . . . . . . . . 39

3.4 Solving the Model . . . . . . . . . . . . . . . . . . 45

3.4.1 System of Equations for Solving . . . . . . . . . . . 45

$\begin{array}{llr}4 & \text { Results } & 49\end{array}$

4.1 The Effect of Taxes . . . . . . . . . . . . . . . . 51

4.2 Maximising (Weighted) Individual After-Tax Income . . . . . 54

4.3 Optimal Tax Levels with Heterogeneous Individuals and No Public Health Effect . . . . . . . . . . . . . . . . 55

4.4 Optimal Tax Levels with Heterogeneous Individuals and Public Health Effect . . . . . . . . . . . . . . . . . . 59 
A.1 Model Variables . . . . . . . . . . . . . . . . . . . . 74

A.2 Model Parameters . . . . . . . . . . . . . . . 75

$\begin{array}{ll}\text { B Derivations } & 77\end{array}$

B.1 Useful Identities . . . . . . . . . . . . . . . . . . . . 77

B.2 Maximise Utility for Individuals . . . . . . . . . . 79

B.3 Maximise Profits . . . . . . . . . . . . . . . . 84

B.4 Government Provision of Healthcare . . . . . . . . . . 85

B.4.1 Maximise Utility Welfare . . . . . . . . . . . . 87

B.4.2 Maximise Health Welfare . . . . . . . . . . . . 89

B.4.3 Maximise Income Welfare . . . . . . . . . . . . . . 91

B.4.4 Maximise GDP . . . . . . . . . . . . . . . . . 94

B.4.5 Maximising Government Objectives . . . . . . . . 96

B.5 Solving the Model . . . . . . . . . . . . . . . . . . . . . 98 


\section{List of Tables}

4.1 Optimal results for each government objective with healthheterogeneous individuals but no public health effect . . . . 56

4.2 Optimal results for each government objective with healthheterogeneous individuals and public health effects . . . . 60 


\section{List of Figures}

4.1 The effects of taxes . . . . . . . . . . . . . . . . 52

4.2 Social welfare with homogeneous individuals . . . . . . . . 53

4.3 Social welfare defined over utility with heterogeneous individuals 54

4.4 Individual utility for different government objectives . . . . . . 58

4.5 Individual after-tax income for different government objectives 59

4.6 Individual health for different government objectives . . . . . . 59 


\section{Chapter 1}

\section{Introduction}

Health is an important aspect of wellbeing, and it interacts with many other aspects of wellbeing, including the ability to earn income and enjoy leisure time. Most governments in the developed world choose to provide some level of subsidised healthcare to their citizens, and this is typically a substantial (and increasing) proportion of the annual government budget. In the OECD, a typical country will spend about $9 \%$ of GDP on publically and privately provided healthcare (OECD, 2017c). This may be for a number of reasons including economic and humanitarian reasons. The primary aim of this work is to investigate the optimal role for government in healthcare provision, including how this varies with different government healthcare allocation preferences. 


\subsection{Definitions}

An important distinction for this work is that between intrinsic health status, health level, and healthcare service provision. Intrinsic health status is the health level that a person would have in the absence of any medical care. Many people will have intrinsically good health and not need any medical care, but others may (for example) have the bad luck to be born with poor health. As intrinsic health status affects the ability of individuals to get insurance - those who are born with bad health are not normally offered insurance - private health insurance is not included in this model.

Health level is the level of wellness a person experiences (after receiving healthcare), including how they feel physically and mentally, how it affects their ability to live the life they choose to lead, and how robust they are to illness and injury. Healthcare service provision relates to the quality and quantity of healthcare services available to help prevent and improve poor health. Good healthcare service provision reduces the duration and effects of illness and increases survival, but people experiencing good health will require lower levels of healthcare services. Conversely, low levels of healthcare service provision can lead to low levels of health, due to the unavailability of simple and standard treatments for minor ailments that then escalate into more major problems.

For the purposes of this work, we assume a single composite level of health that is amenable to treatment. As different individuals have different intrinsic health statuses, this work also aims to understand how individual heterogeneity affects the role of government in healthcare provision. 


\section{$1.2 \quad$ Externalities}

While an individual's health level is obviously of great interest to that individual, it can also be of interest to other individuals - it has externalities. There are three significant types of health-level externality: public health, where one person's poor health increases the risk of another's health being poor (for example, through a contagious disease); economic concerns where one person's treatment for poor health uses up resources that others might otherwise have accessed; and altruistic concerns, where others may feel concern about a person's poor health. This work will also explicitly investigate the effects of the first of these externalities, while the second appears in the budget constraint and the third can be treated mathematically as a special case of the first.

\subsection{This Model}

This work therefore aims to investigate the optimal role for government in healthcare provision with four complicating factors:

- Individual heterogeneity of intrinsic health

- Externalities of health levels

- Imperfect information held by firms and government agents about individuals

- A range of different government objectives (discussed further below) 
It does this by developing and solving a model that allows us to understand the way health, income, consumption, and wellbeing interact with each other and with the provision of healthcare services by the government and the private sector.

The results from the model demonstrate a role for public provision of healthcare when the population is heterogeneous, and the government has high inequality aversion and maximises social welfare defined over individual utility. However, governments that wish to maximise social welfare defined over individual after-tax income should avoid taxing their population for healthcare, especially if they have high inequality aversion, as this may trigger a perverse outcome.

In the following section, an extensive literature review is undertaken to clarify the context for this work. It starts with a discussion on what wellbeing is and how it is described. This is a topic for which there are several different schools of thought, and it is useful to clarify which one this work relates to. Next is an investigation into the role and objectives of government policy. This can involve substantial value judgements, and this is dealt with here by taking a pluralistic approach. The third subsection looks at the various attempts that have been made to measure wellbeing and its various aspects in practice, which is an important consideration for how governments might incorporate the results of this work into their decision-making. Finally, two models (Grossman (1972) and Fleurbaey (2005)) of the interaction between health, healthcare, and income are described. These models are important as they cover many of the same interactions as this work, but with some 
important differences.

After the literature review, the model that is used in this work is described. This is a static model with individual agents who care about their utility, firms that care about their profits, and a government that may care about a range of different objectives including GDP, individual after-tax incomes, health, wellbeing, and inequality.

Once the model is described mathematically, it can be solved numerically. This is done for two individuals with homogeneous or heterogeneous health, with and without taking account of public health, for seven different choices of government objectives, and varying levels of inequality aversion. The implications of these solutions are then be discussed.

The work concludes by bringing together the modelling results to obtain qualitative understanding that can help inform government policy. It also discusses the strengths and weaknesses of the approach, and how this might be improved in future work.

Finally, the first appendix provides a glossary of all the variables and parameters used in this work (including the values used for the numerical solution), and the second appendix contains the detailed mathematical derivations used to develop the model. 


\section{Chapter 2}

\section{Literature}

In this chapter, an extensive literature review is undertaken to clarify the context for this work. It starts with a discussion on what wellbeing is and how it is described. Next is an investigation into the role and objectives of government policy, and the third subsection looks at the various attempts that have been made to measure wellbeing and its various aspects in practice. Finally, two models (Grossman (1972) and Fleurbaey (2005)) of the interaction between health, healthcare, and income are described.

\subsection{Wellbeing of Individuals and Societies}

\subsubsection{What is Wellbeing?}

"Wellbeing" is a term that is used in two main ways. It may be used to refer to subjective wellbeing, or to a more holistic concept that includes substantial 
objective dimensions. Either way, wellbeing is a compound idea that is made up of multiple dimensions.

When "wellbeing" refers to subjective wellbeing, it describes the subjective experience of people, and as such it must be self-reported. It can refer to life satisfaction, positive affect (e.g. feeling happy), or negative affect (e.g. feeling sad). It (usually implicitly) incorporates people's preferences. According to welfarist approaches, subjective wellbeing is the primary measure of overall wellbeing, akin to economists' traditional understanding of "utility" (Bentham, 1789). Other dimensions of wellbeing, such as income, health, other material standard-of-living indicators, and other quality-of-life indicators, are contributors to subjective wellbeing. This is the position of Layard (2005) and of Helliwell, Layard, and Sachs (2015). However, this approach can come with significant measurement challenges, particularly when trying to measure life satisfaction. Lucas (2016) summarises some of the challenges in measuring subjective wellbeing; these include the effects of short-term influences on the respondent that should not affect their estimation of their long-term life satisfaction such as question order, the local weather (distinct from climate), and the mood of the respondent. It can also fail to distinguish high life satisfaction due to low expectations; and high positive affect (for example) due to drug taking from high subjective wellbeing due to a higher quality of life.

The second main usage of "wellbeing" in the economics literature has a broader meaning, and relates to the capability approach of Sen and others (see for example Sen (1999) and Sen (2009)). In the capability approach, the 
emphasis is on the capability of individuals to live the life they have reason to value, and thus health, education, the environment, and other dimensions are as important as material wellbeing. Many of these capabilities can be measured in objective terms; but an individual's preferences become important when one capability must be traded against another. In addition, there is no standard way of describing the capabilities or measures that should be included in this definition of wellbeing. A review of the dimensions that could be important is given in Alkire (2002).

In the health literature, wellbeing (usually in a health sense) is commonly measured by Quality-Adjusted Life Years (QALYs) or Disability-Adjusted Life Years (DALYs). QALYs are measured relative to perfect health, which takes the value 1 for each year of perfect health, and a lower value (determined from empirical studies) for each year of imperfect health. DALYs are measured as number of years lost due to premature death, plus disability(and sometimes age-) weighted years spent with some type of disability. In both cases, these measures are intended to help quantify the effect of health on quality of life and ability to function. However, they are a health-specific measure, and so do not take into account (for example) the effect of income on quality of life, nor do they explicitly ${ }^{1}$ take into account the interaction between health and income.

In this work, "wellbeing" will refer to the second (capability approach) definition of wellbeing, unless it is explicitly referred to as "subjective wellbeing". This corresponds with the meaning used by Stiglitz, Sen, and Fitoussi (2009)

\footnotetext{
${ }^{1}$ This interaction may be taken into account implicitly, depending on the methodology used to determine the quality or disability weights.
} 
and most of the wellbeing measures described later in section 2.3 including the OECD Better Life Index (OECD, 2017a) and their How's Life series (OECD, 2011); this type of wellbeing can also be influenced by government policy more directly.

\subsubsection{GDP and Wellbeing}

Traditionally, GDP (Gross Domestic Product) has been used as a measure of wellbeing when comparing countries, partially due to its standardised measurement and single value, and partially due to the belief that income level (despite the fact GDP measures production ${ }^{2}$ ) is a good proxy for wellbeing. Standardised measurement is a very helpful feature to have for any internationally and intertemporally compared indicator, and a single value (as opposed to, for example, a dashboard) is a valuable communication tool.

However, the belief that GDP is a good measure of welfare or wellbeing is subject to much criticism; and is not the intended purpose of GDP. Simon Kuznets, one of the original developers of GDP and GNI (Gross National Income), stated "The welfare of a nation can, therefore, scarcely be inferred from a measurement of national income as defined above." (Kuznets, 1934, p. 7). The System of National Accounts (UN, 2008) explicitly states that GDP is not appropriate as a measure of welfare (paragraph 1.75). There are a number of reasons for this, including that GDP includes production of "regrettables" such as pollution (Nordhaus and Tobin, 1972); that it does not

\footnotetext{
${ }^{2}$ GNI, by contrast, measures Gross National Income. In each case, depreciation should be deducted to come closer to a measure of material wellbeing, so NNI (Net National Income) may be the best national accounts proxy of material wellbeing.
} 
include unmonetised production such as the cooking, cleaning, and childcare that occurs within a family unit and may contribute substantially to welfare (Waring and Steinem, 1988); it does not distinguish between sustainable production and that which depletes capital of any type nor does it distinguish between increased production for normal reasons and increased production to deal with a problem like destruction caused by a major earthquake (Nordhaus and Tobin, 1972); and it ignores the fact that welfare and wellbeing are not just about economic or material wellbeing (Stiglitz, Sen, and Fitoussi, 2009). In the last decade or so, the belief in income and GDP as good proxies for wellbeing has been increasingly challenged by popular opinion as well as a variety of authors.

The use of GDP or income as measures of wellbeing also raises the Easterlin paradox. In this paradox, raised by Richard Easterlin (1974, see also Easterlin et al., 2010), within a country richer people tend to be happier than poorer people at any given time; but as GDP changes over time average happiness is (broadly) unchanged. This paradox can be resolved if it is income relative to one's near neighbours that is important for happiness rather than absolute income levels. The paradox is also resolved if people become habituated to recent levels of material wellbeing and so their happiness reverts to a stable 'set-point' if they do not keep increasing their income (possibly at a faster rate). However, Stevenson and Wolfers (2008) suggest that poor data (both lack of data and measurement issues), regressing on income instead of log-income, and conflating happiness with life satisfaction have led to these conclusions; and once these problems are addressed there is a positive relationship between GDP and life satisfaction over time and 
across countries with no saturation point. In addition, the subjective wellbeing of an individual has also been shown to be sensitive to differences in GDP per capita between their own country and other countries (Becchetti et al., 2013; Grimes and Reinhardt, 2015).

\subsubsection{Wellbeing of Individuals}

At an individual level, wellbeing encompasses the things an individual values as contributing to their quality of life. This includes their material conditions such as their financial wealth and their consumption, but it also includes things money can't always buy, such as good health, clean air, and quality friendships. Individuals will value these things differently according to their preferences, which then makes it difficult to come up with a single valueneutral number representing wellbeing from a dashboard approach.

It is also useful to think about the distinction between utility and capability. Both are important. Utility can be described as the value we get from the ends - how much we can consume, how healthy we are, how many quality friendships we have etc. The capability approach (as described by Sen in his body of work such as Sen, 1999 and Sen, 2009), is more about the process and choices available to individuals, such as the freedom good health gives to choose to earn more income or to further one's education. The capability approach highlights the importance of the linkages between different aspects of wellbeing. The greater our capability, the more opportunity we have to make choices that maximise our utility even if we change our preferences. 


\subsubsection{Wellbeing of Society}

At the societal level, we face the additional challenge of aggregation across individuals when attempting to understand wellbeing, and this, like combining different aspects of well-being, is not value-neutral (see, for example, the argument by Robbins (1932)). Sen (2009) illustrates this in relation to the capability approach by posing a conundrum: should person A be the recipient of a good as they are the most needy, person B as they put in the most effort, or person $\mathrm{C}$ as they can pay the most? Clearly, any answer to this case is a value judgement and cannot be determined objectively. In this context, wellbeing faces the same practical and philosophical challenges as utility when aggregating across individuals.

There are some principles that are useful to consider when comparing or aggregating wellbeing across individuals. These include the Pareto principle which can give a partial ordering by stating that the wellbeing of society is greater in one state than another if the wellbeing of at least one person in that state is higher, and no person is worse off in terms of their own wellbeing. Another is the impartiality principle of Harsanyi (1977), where "there are occasions when people make, or are at least expected to make, a special effort to assess social situations from an impartial and impersonal point of view, giving equal weight to the legitimate interests of each participant" (p. 48). Harsanyi does not explicitly elaborate on what legitimate interests might be, but does suggest judges and public officials would be expected to be guided by such a principle, as well as any person who makes a "moral value judgement". 
Another principle useful to consider in this context is the Rawlsian "veil of ignorance". According to this principle, choices relating to social welfare will be impartial or just if they are made without knowing the social positions or preferences of individuals (Atkinson and Stiglitz, 1980), especially those individuals who are making the decisions.

One characterisation of this approach is the maxi-min social welfare function $W$, which maximises the utility $U_{i}$ of the worst-off individual $i$ :

$$
W=\min _{i}\left(U_{i}\right)
$$

This function is chosen on the basis that if an individual doesn't know what their position in society will be, they will want to choose a society where the worst possible outcome they could face will be better than it is in any other society. However, this ignores the rest of the distribution, and even taking into account the veil of ignorance, a society with one very low-utility individual and many very high-utility individuals may be preferable to a society with one moderately low-utility individual and many slightly low-utility individual due to the higher chance of being high-utility. More specifically, in a two-person society the maxi-min approach would recommend choosing the allocation $(100,101)$ over $(99,200)$ even though individuals operating behind a Rawlsian veil of ignorance might prefer the latter allocation.

At a different extreme is the Benthamite objective of maximising the sum of individual utilities (Atkinson and Stiglitz, 1980):

$$
W=\sum_{i} U_{i}
$$


Although this includes everyone in the society, unlike the maxi-min approach, it is still compatible with many different distributions. Increasing the social welfare of this society can be achieved by increasing the utility of the lowestutility individual (as in the maxi-min approach), but this has the same effect on overall social welfare as increasing the utility of the highest-utility individual by the same amount.

The maxi-min $(\nu \rightarrow \infty)$ and Benthamite $(\nu=0)$ cases can both be summarised by the isoelastic formulation (Atkinson and Stiglitz, 1980):

$$
W=\frac{1}{1-\nu} \sum_{i}\left[U_{i}^{1-\nu}-1\right]
$$

This formulation also allows intermediate cases which take into account the distribution of utilities, while putting a higher weight (higher value for $\nu$ ) on those in the society who have lower utility. Each of these approaches, however, suffers from the traditional issue of inter-personal utility comparisons which led to the adoption of the revealed preference approach (Samuelson, 1938). However, the revealed preference approach is based on individuals' choices rather than their observed wellbeing or utility and so is difficult to incorporate into an explicit wellbeing approach to policy. For this reason, the revealed preference approach is not pursued further.

\subsection{Objectives of Government Policy}

If wellbeing is considered in the sphere of public policy, it is also important to consider the role of government-another value judgement. Is the role of 
government and public policy to "improve peoples lives, now and into the future" as suggested by Karacaoglu (2015, p. 1)? Or is it much narrower, limited to the minimal state providing basic protections against fraud, theft, and violence as described by Nozick (1974)? In a democracy such as New Zealand, those in power with the consent of the population determine the answers to these questions.

Nozick argues for a very limited state, where the state's role is "limited to the narrow functions of protection against force, theft, enforcement of contracts, and so on", where anything more extensive "will violate persons' rights not to be forced to do certain things, and is unjustified" (1974, p. ix). In this statement, he is referring to a state with coercive powers, and does not rule out voluntary collaborations that are far less limited. He allows a coercive tax to finance this operation of government to circumvent free-rider problems. If public policy is limited to operating in this narrow definition of the state, there is little role for government wellbeing policy beyond that delivered by living in a society with an effective legal structure.

Atkinson and Stiglitz (1980) suggest that Nozick's minimal state could be increased with little controversy by allowing the government to also enact "universally approved" activities. This allows Pareto improvements, where at least one individual is made better off and no one is made worse off. As this in theory requires no coercion, it could also be achieved voluntarily in Nozick's state. This includes situations where the conditions for the first and second theorems of welfare economics do not hold, for example, if competition is imperfect (perhaps because of small market size), or if infor- 
mation is imperfect. Correcting these market failures would then achieve a Pareto-efficient outcome (if a competitive equilibrium exists) according to these theorems.

A more interventionist role for the state involves redistributive policies that are not Pareto-improving, making some individuals worse off than they would otherwise be (in the process of making others better off). This is common practise internationally, with many states (including New Zealand) practising some level of income redistribution as well as public provision of goods and services such and education and healthcare. However, the extent and nature of such redistribution requires significant value judgements.

A recent paper (Odermatt and Stutzer, 2017) begins with "It is self-evident that public policy should be oriented towards the well-being of the people." This is compatible with the Rawlsian veil of ignorance (Rawls, 1971), Harsanyi's impartiality principle (1977), and Sen's capability framework (Sen, 1999; Sen, 2009), but it requires somewhat more extensive government intervention and possibly coercion than Nozick's limited state (1974). The same paper (Odermatt and Stutzer, 2017) then continues "It is similarly self-evident that views differ regarding what well-being means and what contributes to well-being.", as discussed in section 2.1.1.

As this work is investigating health, income, and their interactions with wellbeing, there are several possible "views on well-being" a government might have:

- Utility: Utility can be considered a measure of wellbeing, but is reliant on knowing the preferences of the individuals experiencing the 
wellbeing.

- Health: Health is generally considered to be an important contributor to capability and wellbeing, and is more easily measured than utility, but it misses other important contributors to wellbeing.

- After-tax (disposable) Income: Income is traditionally used as a proxy for wellbeing, with the idea that it can be used as the individual desires to purchase other contributors to wellbeing such as healthcare services. However, material wellbeing is only one part of wellbeing and, in our current context, this approach ignores health outcomes.

- GDP: Although (as explained above) GDP is not a measure of wellbeing or welfare, increasing GDP has been a significant focus of many governments in the past few decades. This is due to the idea of the "trickle-down effect", where an increase in GDP will (eventually) cause an increase in incomes (and, by extension, wellbeing) for all.

Inequality can be taken into account (using for example the isoelastic formulation of equation (2.3)) when looking at the whole of society for utility, health, and after-tax income as these are measures for individuals; but not for GDP as that is already a whole-of-society measure. Even then, however, one could devise an inequality-adjusted GDP measure by, for instance, interacting a Gini coefficient for income with GDP.

In this work, a pluralistic approach considering each of these possibilities is taken in the spirit of Robbins (1932), to help develop an understanding of the consequences of choosing any one of these options. 


\subsection{Wellbeing Measurement and Modelling}

Much of the current effort studying wellbeing is in developing frameworks, defining, and measuring wellbeing. This has led to a proliferation of indexes, many covering a similar set of aspects of wellbeing, but dividing wellbeing into different categories and using different measures and weights. Each index is designed with a different purpose in mind and makes different value judgements. No one measure or framework is dominant yet.

One of the earliest explicit wellbeing measures to be developed was the UNDP's Human Development Index (UNDP, 1990). In the initial report it describes the HDI as a "move in the right direction" (p. 1) by considering life expectancy and knowledge levels as well as national income, rather than the final word in measuring what is important for human development. The primary reason the UNDP choose to include the indicators they do is their statistical availability, reliability, and international comparability for most countries in the world and particularly the less-developed countries they are most interested in. These indicators are converted to indexes (using the log of real ppp-adjusted GDP per capita and the levels of the other indicators) then averaged to create the final values for the Human Development Index. This indicator continues to be used in their annual reports, including the latest (UNDP, 2016).

The World Bank uses Adjusted Net Savings, also known as Genuine Savings (Hamilton, 2000), which emphasises sustainability through measuring changes to capital stocks. Hamilton takes the standard measures of economic capital savings, then adjusts them for changes in natural resources, 
pollutants (proxied by carbon emissions), and human capital. To do this, prices must first be found for each natural resource, pollutant, and human capital; and the final level of genuine savings is reported as a monetary value. This then provides an indicator of sustainability - countries or regions with a negative genuine savings are drawing down their net level of capital, which, if continued indefinitely, would lead to serious problems. The quality of genuine savings as a sustainability predictor was investigated by Greasley et al. (2014) in the long run for Britain, finding it could be a suitable forwardlooking indicator of future wellbeing over timeframes as long as 100 years. The OECD's Better Life Index (OECD, 2017a; OECD, 2011) divides wellbeing into eleven different dimensions, namely civic engagement, community/social connection, jobs, education, environment, health, housing, income and wealth, personal safety, subjective wellbeing, and work-life balance. These dimensions are then measured by 1-4 indicators each, chosen for their international comparability among other features. The OECD do not apply weights to each dimension to obtain an overall wellbeing score -instead, they encourage visitors to their website to enter their own weightings. The records they have kept of the weights entered on their website give a valuable, if biased, indication of the importance of each dimension. In Rijpma et al. (2017), the Better Life Index has been applied to and adapted for The Netherlands, with an overall indicator calculated. Importantly, this indicator is subjected to sensitivity testing, including for the form of the aggregation function. The Better Life Index is also under consideration in New Zealand for adoption as part of the New Zealand Treasury's refreshed Living Standards Framework (King, Huseynli, and MacGibbon, 2018). 
The UN Sustainable Development Goals (UN, 2015) are not described as a measure of wellbeing, but do measure countries against targets that cover a similar range as other measures of wellbeing. There are 169 targets that make up the 17 Sustainable Development Goals, covering people, planet, prosperity, peace, and partnership; and they are intended as goals to make the world a better place relative to how it was when the goals were declared in 2015. These goals are also emphasised as "integrated and indivisible", indicating that if the means of obtaining one target is at the cost of significantly reducing performance against another target, it is unlikely to be considered an acceptable means of reaching that target. Multiple indicators and indexes to measure progress against the targets have been created, for example, (Sridhar, 2016; SDSN, 2015; OECD, 2017b).

Some not-for-profit and many non-governmental organisations have developed their own measures, including the Legatum Institute's Prosperity Index (2016) and the New Economics Foundation's Happy Planet Index (Abdallah et al., 2009). The Prosperity Index has 104 variables spread across 9 pillars that cover similar dimensions as the OECD Better Life Index, which are weighted and averaged to form subindices and the overall index. The Happy Planet Index is created from three components - health, and positive experience of life, and ecological footprint - in a complex formula that can be very roughly represented as happy life years divided by ecological footprint. In addition to these measures, there are also regular reports ranking the "best" cities to live in, such as the Global Liveability Ranking (The Economist, 2016), and in New Zealand The Treasury have used their Living Standards Framework (Gleisner, Llewellyn-Fowler, and McAlister, 2011) as 
a qualitative tool for policy analysis.

All of these frameworks run into statistical, methodological, and value problems. Frequently, the required data isn't available, isn't internationally comparable, or has measurement issues. Methodologically, converting indicators into commensurate values that can be compared is difficult and there is no clear best way to do so. Methodological and statistical issues are noted as issues in most of these measures. Less often noted or discussed are the value problems (as noted in Stiglitz, Sen, and Fitoussi (2009)), where the way the indicators are combined requires an implicit or (more rarely) an explicit judgement. Of the indicators described above, only the OECD proposes a solution to this problem, by letting users of the index chose their own weightings between dimensions (although they still combine their Better Life Index indicators within each dimension ${ }^{3}$ ). As such, most of these measures of wellbeing are not as objective as they might claim to be.

Note also that measurement (and to a lesser degree regression) doesn't directly help us to understand the impacts of different policy settings and understand their interaction, and there is much less literature on creating a model of wellbeing. Most of the current and historical work is theoretical and only brings one or two aspects of wellbeing together, most commonly growth or income and the environment. This includes applying viability theory to explore the boundaries of sustainable satisficing in fisheries (Krawczyk et al., 2013), Arrow et al. work on "comprehensive consumption" (2012, 2013), "clean" and "dirty" technologies (Acemoglu et al., 2016), and adapt-

\footnotetext{
${ }^{3}$ The OECD's How's Life series of reports (OECD, 2011), which uses the same dimensions and most of the same indicators as the Better Life Index, makes no attempt to combine indicators or dimensions
} 
ing growth theory to include the environment (Dasgupta and Heal, 1974). In health economics, the Grossman model (Grossman, 1972) described in section 2.4.1 studies some of the interaction between health and income, as does the Fleurbaey model (Fleurbaey, 2005) described in section 2.4.2. Karacaoglu (2015) pulls together some of these theoretical strands of work to create a more comprehensive theoretical model appropriate for a small open economy such as New Zealand, and King (2018) has designed a comprehensive model as a practical tool for answering policy questions.

\subsection{Models of Health, Income, and Wellbeing}

Theoretical models that investigate the relationship between health, income, and wellbeing are not common. Two are described in some detail here. The Grossman model (Grossman, 1972) is a pioneering model in this field, and is often quoted in subsequent literature. The Fleurbaey model (Fleurbaey, $2005)$ is more recent, and has a similar objective to this work.

\subsubsection{Grossman model}

The Grossman model can be summarised as a dynamic partial equilibrium model for an individual that treats health as a capital stock. An individual in the model face two constraints - a goods budget constraint and a time constraint.

Consider first the time constraint ${ }^{4}$. The total time available $(\Omega=365$ days

\footnotetext{
${ }^{4}$ Grossman's notation is used throughout this section
} 
in the year) must be exhausted by all possible uses (otherwise not all possible uses are included). In the Grossman model, there are four possible uses of time in a time period $i$ : working for wages $T W_{i}$, household production $T_{i}$, investing in health $T H_{i}$, and time lost due to illness $T L_{i}{ }^{5}$. Time lost due to illness is assumed to be inversely related to the stock of health. Note that investing in health - such as preventative check-ups - is distinct from time lost due to illness. Thus, we have:

$$
T W_{i}+T L_{i}+T H_{i}+T_{i}=\Omega
$$

The goods budget constraint is an intertemporal constraint, with the present value of consumption equal to the present value of income plus initial assets $A_{0}$ :

$$
\sum \frac{P_{i} M_{i}+V_{i} X_{i}}{(1+r)^{i}}=\sum \frac{W_{i} T W_{i}}{(1+r)^{i}}+A_{0}
$$

$W_{i}$ is the wage rate, and $P_{i}$ and $V_{i}$ are the prices for medical care $M_{i}$ and purchased goods $X_{i}$. As this is a partial equilibrium model, all prices are exogenous. The purchased goods $X_{i}$ and the time invested in home production $T_{i}$ are combined (along with human capital $E_{i}$ ) in a household production function to obtain consumption of non-health commodity $Z_{i}$. Similarly, the purchased medical care $M_{i}$ is combined with the time invested in healthcare $T H_{i}$ (along with human capital $E_{i}$ ) to obtain the gross investment in health $I_{i}$. As the stock of health cannot be sold, this gross investment must be

\footnotetext{
${ }^{5}$ Leisure - a significant contributor to wellbeing - is not mentioned in Grossman's analysis. However, it could be considered a part of the time spent investing in health.
} 
non-negative. The health level of an individual in time period $i+1$ is then determined by:

$$
H_{i+1}-H_{i}=I_{i}-\delta_{i} H_{i}
$$

where $\delta_{i}$ is the exogenous (but potentially age-dependent) rate of depreciation of health in the $i$ th time period. Note that this allows the length of life to be endogenous - death occurs when $H_{i}=H_{\text {min }}$ and all days are sick days $T L_{i}=$ $\Omega$. Intertemporal utility is then a function of health $H_{i}$ and consumption $Z_{i}$. Grossman then goes on to derive the equilibrium conditions, and use the model to investigate the effects of different depreciation rates, wages rates, and human capital levels. Using the model, he is able to make several predictions. First, if the rate of depreciation increases with age, demand for health capital will decline while expenditure on medical care will increase. Second, demand for health and medical care increases with wages. Third, if more education (higher human capital) increases the efficiency of producing gross improvements in health, then the more educated will demand a higher level of health. He then concludes with "Any model must recognize that health is a durable capital stock, that health capital differs in important respects from other forms of human capital, and that the demand for medical care must be derived from the more fundamental demand for "good health."” (Grossman, 1972, p. 248).

The Grossman model differs from the model proposed in this work in several different ways, including the purpose. The purpose of Grossman's model is to emphasise the importance of treating health as a capital stock; whereas the purpose of this work is to emphasise the role of government in providing 
healthcare as a part of wellbeing along with the interconnectedness of health with the rest of the economy. As the purpose of the models is different, the models themselves also differ. Grossman's model is a dynamic partial equilibrium model that does not have a government and specifically excludes health as having an impact on productivity (except indirectly, through time available to spend working after sick days are removed). The model described in this work is a static general equilibrium model with a government and an impact of health on productivity. However, Grossman's model provides some useful insights, particularly the distinction between healthcare (called "medical services" by Grossman) and health level.

\subsubsection{Fleurbaey Model}

The Fleurbaey model (Fleurbaey, 2005) can be summarised as a static partial equilibrium model with multidimensional health that can be used (in principle) to determine an aggregate healthcare budget for a country. It does this by considering individual preferences of the members of the society along with three ethical principles that most would consider reasonable.

The first of these principles is the standard Pareto principle, where if everyone in the population prefers one alternative to another, the preferred alternative is better.

The second principle is a weakened Pigou-Dalton transfer principle. The original version of this principle says it is a better situation if a richer person transfers some money to a poorer person. However, this can lead to perverse outcomes (as described by Fleurbaey) when individuals have different health 
levels as well as different income levels, or different health preferences. To avoid these issues, Fleurbaey only allows such transfers between individuals who have perfect health or individuals with identical health and preferences. Although this principle is about reducing inequality, it is very weak in that regard and can even be consistent with zero inequality aversion.

The third principle of Fleurbaey's is to use minimal information on individual preferences in determining social preferences. This is partly for data reasons, but also to avoid arbitrating between individuals who have identical consumption and health outcomes but claim to have different preferences and therefore more entitlement. This principle is a weaker version of Arrow's independence of irrelevant alternatives condition.

The budget constraint for an individual $i$ of health $h_{i}$ in Fleurbaey's model ${ }^{6}$ is given by setting non-medical consumption $c_{i}$ equal to the after-tax $\tau$ income $w_{i}\left(h_{i}\right)$ minus medical expenses $m_{i}\left(h_{i}\right)$, after they have been subsidised at rate $\rho$ :

$$
c_{i}=(1-\tau) w_{i}\left(h_{i}\right)-(1-\rho) m_{i}\left(h_{i}\right)
$$

Individuals then choose their most-preferred bundle of goods $z_{i}=\left(h_{i}, c_{i}\right)$ given their budget constraint (2.7).

Fleurbaey then defines $C_{i}\left(z_{i}\right)$ as the smallest level of consumption the individual $i$ would accept as replacement of $c_{i}$ in $z_{i}=\left(h_{i}, c_{i}\right)$, provided there was a suitable improvement in their health. Thus, for a person in near-perfect health, $C_{i}\left(z_{i}\right)$ would be similar to $c_{i}$ as they require little improvement in their health, whereas for a person with poor health and/or who cares sig-

\footnotetext{
${ }^{6}$ Fleurbaey's notation is used throughout this section
} 
nificantly about their health, $C_{i}$ could be quite low relative to $c_{i}$. This is used, along with the three principles described earlier, to come to the conclusion that the best allocation $z=\left(z_{1}, \ldots, z_{n}\right)$ between individuals is found by maximising $\min _{i} C_{i}\left(z_{i}\right)$. Note that this maxi-min criterion, which characterises extreme inequality aversion, was derived with only very weak equity considerations.

In addition to this very general condition, Fleurbaey goes on to calculate an example with one-dimensional health. Consider an individual $i$ with utility $u_{i}$ given by:

$$
u_{i}\left(h_{i}, c_{i}\right)=h_{i}^{a_{i}} c_{i}
$$

earning ability $w_{i}$ given by:

$$
w_{i}\left(h_{i}\right)=\alpha_{i} h_{i}{ }^{\beta_{i}}
$$

and medical expenses $m_{i}$ to get to health level $h_{i}$ given by:

$$
m_{i}\left(h_{i}\right)=\mu_{i} h_{i}^{\gamma_{i}}
$$

This then results in the minimum replacement consumption $C_{i}$ given by

$$
C_{i}\left(z_{i}\right)=\left\{\begin{array}{cc}
\alpha_{i}\left[1-\theta_{i}\right](1-\tau)\left[\frac{1-\tau}{1-\rho} \frac{\alpha_{i}}{\mu_{i}} \theta_{i}\right]^{\frac{\theta_{i}}{1-\theta_{i}}} & \text { if } \theta_{i} \leq \frac{(1-\rho) \mu_{i}}{(1-\tau) \alpha_{i}} \\
(1-\tau) \alpha_{i}-(1-\rho) \mu_{i} & \text { if } \theta_{i} \geq \frac{(1-\rho) \mu_{i}}{(1-\tau) \alpha_{i}}
\end{array}\right.
$$

where

$$
\theta_{i}=\frac{\beta_{i}+a_{i}}{\gamma_{i}+a_{i}}
$$


If the budget of the healthcare provider must be balanced, then:

$$
\tau \sum_{i=1}^{n} w_{i}\left(h_{i}\right)=\rho \sum_{i=1}^{n} m_{i}\left(h_{i}\right)
$$

Unfortunately, if health $h_{i}$ is then substituted into the equation, the expression becomes too complicated to deduce analytical results about optimal choices for $\tau$ and $\rho$ except in a few special situations.

The Fleurbaey model differs from this work in several ways. Although both the Fleurbaey model and the model in this work are static models with the similar purpose of determining the level of healthcare provision in the context of the wellbeing of society, Fleurbaey's model is a partial equilibrium model whereas the model in this work is a general equilbirum model. Fleurbaey's model is both more explicit and more general in the principles it uses, which results in a more theoretical and less analytically tractable model. It also only considers one possible way of aggregating individuals within a society (the maxi-min method), whereas the model presented in this work takes a more pluralistic approach, including allowing different levels of inequality aversion. 


\section{Chapter 3}

\section{Model}

Throughout the model, the simplest possible choices that will still allow interesting model behaviour are made. There are three types of agents - individual, firms, and governments. Individuals have different intrinsic health levels, and firms produce either healthcare or other goods and services. Governments choose the rate of taxation and how public healthcare is distributed between individuals. Each of these agents are constrained by accounting equations. All three types of agents exhibit maximising behaviour, and there are also equations that define variables for each type of agent.

\subsection{Individuals}

Consider an economy with many heterogeneous individuals, with intrinsically different health levels. All individuals maximise their utility from their health level, leisure time, and consumption. They earn income by supplying labour 
to firms, and this income places a constraint on the level of utility they can achieve.

\subsubsection{Definition Equations}

We start by defining individual consumption from all sources, individual income, and health levels.

Individuals can purchase either of the two goods (namely healthcare goods $k=M$ and other goods $k=O)$ in the model from firms, but they can also be given them by the government at no direct cost to the individual. Thus, the total consumption $C_{k, i}$ of any good $k$ by a single individual $i$ is given by:

$$
C_{k, i}=C_{k, i}^{I}+C_{k, i}^{G}, \quad \forall i, k, C_{k, i}^{I} \geq 0, C_{k, i}^{G} \geq 0
$$

where $C_{k, i}^{I}$ is the goods purchased by the individual $i$, and $C_{k, i}^{G}$ is the goods provided to individual $i$ by the government at no direct cost.

Individuals earn income from labour $L_{i}$, where wages $w$ are taxed at rate $\tau$, to get after-tax income of $Y_{i}$ :

$$
Y_{i}=(1-\tau) w L_{i}, \quad \forall i
$$

Taxes $\tau$ and wages $w$ are constant across all individuals, as we assume that firms cannot set wages based on health level (e.g. due to legislative restriction or to imperfect information) and governments choose not to tax based on health level or other individual characteristics. These assumptions could be relaxed in extensions to the model. 
The average health level of an individual $i$ is assumed to be a deterministic function of intrinsic health level $H_{0, i}$, healthcare services $C_{k=M, i}$ received from any source, and (when considering public health) the average health of all individuals in the society $H_{S}{ }^{1}$ :

$$
H_{i}=H_{i}\left(H_{0, i}, C_{k=M, i}, H_{S}\right), \quad \forall i
$$

There are several desirable properties for a function for health level. Firstly, healthcare should not decrease health level. This means that when healthcare is zero (and ignoring public health influences), the health level should be the same as the intrinsic health level $H_{0, i}$, and health level should increase monotonically from there as healthcare provision increases. Secondly, a higher level of health in society should weakly increase an individual's health level. Least importantly, the mathematics for the model is simpler if health level is linearly depend on healthcare provision, given there is no compelling reason to have a non-linear dependence. The following specific choice of functional form for health level meets these criteria:

$$
H_{i}=H_{S}{ }^{\gamma_{i}}\left(H_{0, i}+\xi_{i} H_{0, i}{ }^{-\beta_{i}}\left(C_{k=M, i}^{I}+C_{k=M, i}^{G}\right)\right), \quad \forall i
$$

$\gamma_{i} \geq 0$ is a parameter that determine the effect of society's health, $\xi_{i} \geq 0$ is a parameter that characterises the effectiveness of the healthcare provision

\footnotetext{
${ }^{1}$ Note that leisure and wellbeing have not been included in the function for health level, as these would add significant complication and are instead are left to future work. It is well-established that not only does good health improve wellbeing, but that a high level of wellbeing also improves health, as shown in (for example) Danner, Snowdon, and Friesen (2001).
} 
for that individual, and $\beta_{i}$ describes how strongly the intrinsic health level moderates the effect of healthcare provision. If $\beta_{i} \geq 0$, individuals with lower intrinsic health will benefit more from the provision of healthcare than those with higher intrinsic health.

\subsubsection{Accounting Equations}

Some equations must hold as identities, and time and budget constraints fit into this category.

Individuals face a time constraint, where the time spent on all activities must add up to the total time available. In this model, there are two activities, namely leisure $l_{i}$ and (paid) labour (supply) $L_{i}$, and if these are measured as a proportion of total time available, then:

$$
1=L_{i}+l_{i}, \quad \forall i
$$

Note that this does not explicitly incorporate a separate time category for time spent on healthcare activities including visiting the doctor and exercising (unlike Grossman (1972)), but this could be considered as an extension to the model.

Individuals also face a financial budget constraint. As there is no borrowing or saving in the model, individuals spend all their income on healthcare and other goods, purchased at prices $P_{k}$ :

$$
Y_{i}=\sum_{k} P_{k} C_{k, i}^{I}, \quad \forall i
$$


In addition, the societal health level $H_{S}$ is defined as the average health of the population:

$$
H_{S}=n^{-1} \sum_{i} H_{i}
$$

where $n$ is the total number of individuals in the population.

\subsubsection{Behaviour Equations}

The standard assumption of maximising utility is used, where utility $U_{i}$ is a function of health $H_{i}$, leisure $l_{i}$, and total other consumption $C_{k=O, i}$ :

$$
U_{i}=U_{i}\left(H_{i}, l_{i}, C_{k=O, i}\right), \quad \forall i
$$

Note that healthcare consumption does not contribute to wellbeing directly, but only indirectly through health level, as individuals are much less interested in receiving healthcare for its own sake than in the health benefits it brings.

For simplicity, choose the Cobb-Douglas function as the specific functional form for utility:

$$
U_{i}=H_{i}{ }^{\mu_{H, i}} l_{i}{ }^{\mu_{l, i}} C_{k=O, i}{ }^{\mu_{k=O, i}}, \quad \forall i
$$

where, without loss of generality,

$$
\mu_{H, i}+\mu_{l, i}+\mu_{k=O, i}=1
$$


Using the Lagrangian method (with details of the derivation in the Appendix, and assuming an interior solution), the individual's demand for leisure is given by:

$$
l_{i}=\mu_{l, i}\left[1+\frac{P_{k=M}}{(1-\tau) w}\left(C_{k=M, i}^{G}+\xi_{i}^{-1} H_{0, i}{ }^{1+\beta_{i}}\right)\right]
$$

and the individual's demand for "other" and "healthcare" goods respectively is given by:

$$
C_{k=O, i}^{I}=\mu_{k=O, i}(1-\tau) w P_{k=O}{ }^{-1}\left[1+\frac{P_{k=M}}{(1-\tau) w}\left(C_{k=M, i}^{G}+\xi_{i}{ }^{-1} H_{0, i}{ }^{1+\beta_{i}}\right)\right]
$$

and

$$
C_{k=M, i}^{I}=\mu_{H, i}(1-\tau) w P_{k=M}{ }^{-1}-\left(1-\mu_{H, i}\right)\left(C_{k=M, i}^{G}+\xi_{i}{ }^{-1} H_{0, i}{ }^{1+\beta_{i}}\right)
$$

\section{$3.2 \quad$ Firms}

The economy in this model has two types of firms. One type produces healthcare services $(k=M)$, and the other $(k=O)$ produces everything else. Both firms are profit-maximising, operate in a perfectly competitive environment, and use labour $L_{k, i}$ (but no capital) from each individual. 


\subsubsection{Definition Equations}

Production $Q_{k}$ is a function of labour $L_{k}$ :

$$
Q_{k}=Q_{k}\left(L_{k}\right)
$$

where $L_{k}$ is the sum of the health-adjusted labour $H_{i} L_{k, i}$ supplied by each individual for that production process:

$$
L_{k}=\sum_{i} H_{i} L_{k, i}, \quad \forall k
$$

Labour is adjusted for health as poor health can negatively impact productivity both in sick days paid for by employers and in "presenteeism" where sick employees show up to work but are much less productive than healthy employees. Once adjusted for health level, labour from any individual is perfectly substitutable with labour from any other individual. Note that this production function does not include capital, as that would be an unnecessary complication for this model.

A simple functional form is then chosen for the production function:

$$
Q_{k}=A_{k} L_{k}, \quad \forall k
$$

where $A_{k}$ is the multi-factor productivity for each type of production. 


\subsubsection{Behaviour Equations}

Firm behaviour is characteristed by profit maximisation, and subject to a production function. Profits $\pi_{k}$ for the firms are given by:

$$
\pi_{k}=P_{k} Q_{k}-w \sum_{i} L_{k, i}, \quad \forall k
$$

where $w$ is the wage level for each individual, and $L_{k, i}$ is the labour supplied by each individual $i$ to a firm $k$. Firms are assumed to operate under conditions of imperfect information, and so cannot set wages based on an individual's health level ${ }^{2}$. Profits are maximised subject to the production function (3.16) (as shown in the Appendix), which results in zero profits meaning firms operate under perfect competition. Thus, total revenue must equal total costs, giving the firm's budget equation:

$$
P_{k} Q_{k}=w \sum_{i} L_{k, i}, \quad \forall k
$$

Summing across all firms, wages are then given by

$$
w=\frac{\sum_{k} P_{k} Q_{k}}{\sum_{i} L_{i}}
$$

\subsubsection{Accounting Equations}

The accounting identities that affect firms include the market-clearing conditions for goods and labour.

\footnotetext{
${ }^{2}$ Alternatively, anti-discrimination laws may prevent payments at different rates. These assumptions could be relaxed in future work.
} 
When the goods markets clear, the supply of each good $Q_{k}$ equals the total demand for each good:

$$
Q_{k}=\sum_{i} C_{k, i}
$$

This implicitly includes both the individual $C_{k, i}^{I}$ and government $C_{k, i}^{G}$ purchases of each good.

Similarly, when the labour markets clear, the supply of labour by each individual $L_{i}$ equals the total labour supplied to firms from each individual:

$$
L_{i}=\sum_{k} L_{k, i}
$$

It is also necessary to link the total amount of labour used in production to the amount supplied by each individual. This is done by assuming that the amount supplied by any individual to a firm is supplied in proportion to that individual's proportion of the total health-adjusted supply of labour:

$$
L_{k, i}=\frac{L_{i}}{\sum_{i} H_{i} L_{i}} L_{k}
$$

Equations (3.21) and (3.22) together provide the labour market clearing condition. 


\subsection{Government}

The government agents include a taxation agent (e.g. Inland Revenue), that sets the tax rates; a budget-balancing agent (e.g. Treasury) that ensures government expenditure equals government income; and a healthcare provision agent (e.g. Ministry of Health) that distributes healthcare between different individuals. These government agents may or may not have or share information (particularly the intrinsic health status of individuals, but also income levels, tax payments, etc) between themselves.

\subsubsection{Definition Equations}

Government income $Y_{G}$ is the total income from taxes $\tau$ :

$$
Y_{G}=\tau w \sum_{i} L_{i}
$$

As the tax rates are the same for all individuals, this implies the tax agency does not have (or chooses not to use) health information about each individual type.

\subsubsection{Accounting Equations}

The government budget is balanced, with government income equal to spending:

$$
Y_{G}=\sum_{k} P_{k} C_{k}^{G}
$$


Government spending on consumption is equal to the total provided to each individual:

$$
C_{k}^{G}=\sum_{i} C_{k, i}^{G}
$$

\subsubsection{Behaviour Equations}

The behaviour equations for the government agents describe how the government distributes its expenditure across different goods and different individuals.

Assume first that the government does not purchase any "other" goods:

$$
C_{k=O, i}^{G}=C_{G, k=O}=0, \quad \forall i
$$

Because of this, all government income is spent on healthcare and equations (3.23) and (3.24) become

$$
C_{k=M}^{G}=\tau w P_{k=M}{ }^{-1} \sum_{i} L_{i}
$$

The government can distribute healthcare services between individuals in multiple ways, which will be dependent on how much information they have about the individuals, and particularly their health status. The behaviour of government will also be affected by the social welfare function the government chooses to maximise. Four options will be considered here. Of these four options, utility of individuals is the goal that makes the most sense - all the other options are satisficing alternatives that could be used in the situations 
where there is insufficient data about individuals, and in particular their preferences.

\section{Social Welfare from Individual Utility}

A government that is interested in the wellbeing of its citizens would prefer to maximise utility (from health, leisure, and consumption), likely putting some greater emphasis on improving the wellbeing of lower-utility individuals. From the isoelastic formulation of Atkinson and Stiglitz (1980), given earlier in equation (2.3), the social welfare function is given by:

$$
W_{U}=\frac{1}{1-\nu} \sum_{i}\left[U_{i}^{1-\nu}-1\right]
$$

where a higher $\nu$ implies a greater emphasis on disadvantaged individuals. Maximising this, the optimal distribution of healthcare by the government is given by:

$$
\begin{aligned}
C_{k=M, i}^{G}= & \frac{\mu_{H, i} U_{i}{ }^{1-\nu}}{\sum_{i} \mu_{H, i} U_{i}{ }^{1-\nu}}\left(C_{k=M}^{G}+\sum_{i} \xi_{i}{ }^{-1} H_{0, i}{ }^{1+\beta_{i}}+(1-\tau) n w P_{k=M}{ }^{-1}\right) \\
& -(1-\tau) w P_{k=M}{ }^{-1}-\xi_{i}{ }^{-1} H_{0, i}{ }^{1+\beta_{i}}
\end{aligned}
$$

(as derived in the Appendix). Note that, to know the utilities of individuals, governments must know the preferences of those individuals-information they often cannot easily obtain. 


\section{Social Welfare from Individual Health}

The government may not be able to directly observe the utility of its citizens, and so instead may choose to use health as a proxy:

$$
W_{H}=\frac{1}{1-\nu} \sum_{i}\left[H_{i}{ }^{1-\nu}-1\right]
$$

With this social welfare function, health could be considered a more-easily measured proxy for utility. Alternatively, it could be considered important in its own right (at least when $\nu$ is large), as in the concept of "specific egalitarianism". This is a concept introduced by Tobin (1970), which allows for general inequality (for example, as a reward to effort), but suggests that this should not apply to all commodities - some commodities such as basic necessities of life, health, and citizenship, should be available to some extent to all, regardless of ability to pay for them. Slesnick (1989) quotes healthcare provision as an easier-to-justify application of specific egalitarianism, reflecting the "fundamental right to life" (p. 116).

Maximising the isoelastic function (3.30), the optimal distribution of healthcare by the government is then given by:

$$
\begin{aligned}
C_{k=M, i}^{G}= & \frac{H_{i}{ }^{1-\nu}}{\sum_{i} H_{i}{ }^{1-\nu}}\left(C_{k=M}^{G}+\sum_{i} \xi_{i}{ }^{-1} H_{0, i}{ }^{1+\beta_{i}}+(1-\tau) n w P_{k=M}{ }^{-1}\right) \\
& -(1-\tau) w P_{k=M}{ }^{-1}-\xi_{i}{ }^{-1} H_{0, i}{ }^{1+\beta_{i}}
\end{aligned}
$$

(as derived in the Appendix). Health information of individuals is often available to the health ministry of a government, who may also be in charge 
of distributing healthcare, so this method of distributing public healthcare is much less likely to suffer from the imperfect information challenges that social welfare defined over utility faces.

\section{Social Welfare from Individual After-Tax Income}

Governments are often interested in the after-tax incomes of their citizens, particularly the most disadvantaged, as another proxy for utility:

$$
W_{Y}=\frac{1}{1-\nu} \sum_{i}\left[Y_{i}^{1-\nu}-1\right]
$$

Then the optimal distribution of healthcare by the government is given by:

$$
\begin{aligned}
C_{k=M, i}^{G}= & \frac{H_{i} Y_{i}^{-\nu}\left(H_{S}{ }^{\gamma_{i}} \xi_{i} H_{0, i}{ }^{-\beta_{i}}\right)^{-1}}{\sum_{i} H_{i} Y_{i}^{-\nu}\left(H_{S}{ }^{\gamma_{i}} \xi_{i} H_{0, i}{ }^{-\beta_{i}}\right)^{-1}} \\
& \quad \times\left(C_{k=M}^{G}+\sum_{i} \xi_{i}{ }^{-1} H_{0, i}{ }^{1+\beta_{i}}+(1-\tau) n w P_{k=M}{ }^{-1}\right) \\
& -(1-\tau) w P_{k=M}{ }^{-1}-\xi_{i}{ }^{-1} H_{0, i}{ }^{1+\beta_{i}}
\end{aligned}
$$

(as derived in the Appendix). Income information is typically held by the taxation agent, so they will need to be able to share this with the health ministry (and combine it with the health ministry's health data) for this distribution of healthcare to be implemented. 


\section{Social Welfare from GDP}

Sometimes governments are characterised as aiming to maximise GDP, as a proxy for the incomes of their citizens. The social welfare function $W_{G D P}$ is then given by:

$$
W_{G D P}=\sum_{k} P_{k} Q_{k}
$$

where GDP has been defined in terms of production (rather than consumption, although that would be equivalent). Note that this is still subject to individuals choosing their optimal combination of health, consumption, and leisure; but it makes no allowance for inequality aversion. Then the optimal distribution of healthcare by the government is given by:

$$
\begin{aligned}
C_{k=M, i}^{G}= & \frac{H_{i} L_{i}}{\sum_{i} H_{i} L_{i}}\left(C_{k=M}^{G}+\sum_{i}{\xi_{i}}^{-1} H_{0, i}{ }^{1+\beta_{i}}+(1-\tau) n w P_{k=M}{ }^{-1}\right) \\
& -(1-\tau) w P_{k=M}{ }^{-1}-\xi_{i}{ }^{-1} H_{0, i}{ }^{1+\beta_{i}}
\end{aligned}
$$

(as derived in the Appendix). Labour information may be held by the taxation agent or a national statistical agency, and they will need to be able to share this with the health ministry (and combine it with the health ministry's health data) for this distribution of healthcare to be implemented. 


\section{Distribution of Healthcare}

In each of the four cases above, the distribution of healthcare can be represented by the same equations if we define the ratio $\rho_{i}$ as:

$$
\rho_{i}=\left\{\begin{array}{cc}
\frac{\mu_{H, i} U_{i}{ }^{1-\nu}}{\sum_{i} \mu_{H, i} U_{i}{ }^{1-\nu}} & \text { for the utility objective } \\
\frac{H_{i}{ }^{1-\nu}}{\sum_{i} H_{i}{ }^{1-\nu}} & \text { for the health objective } \\
\frac{H_{i} Y_{i}{ }^{-\nu}\left(H_{S} \gamma_{i} \xi_{i} H_{0, i}-\beta_{i}\right.}{\sum^{-1}} & \text { for the income objective } \\
\sum_{i} H_{i} Y_{i}{ }^{-\nu}\left(H_{S} \gamma_{i} \xi_{i} H_{0, i}{ }^{-\beta_{i}}\right)^{-1} & \\
\sum_{i} H_{i} L_{i} & \text { for the GDP objective }
\end{array}\right.
$$

The equations for distributing healthcare are then:

$$
\begin{aligned}
C_{k=M, i}^{G}= & \rho_{i}\left(C_{k=M}^{G}+\sum_{i} \xi_{i}{ }^{-1} H_{0, i}{ }^{1+\beta_{i}}+(1-\tau) n w P_{k=M}{ }^{-1}\right) \\
& -(1-\tau) w P_{k=M}{ }^{-1}-\xi_{i}{ }^{-1} H_{0, i}{ }^{1+\beta_{i}}
\end{aligned}
$$

and the total amount of healthcare provided by the government (as derived in the Appendix) is then:

$$
\begin{aligned}
C_{k=M}^{G}=\left(1+\frac{\tau}{1-\tau} \sum_{i} \mu_{l, i} \rho_{i}\right)^{-1} & \left(n \tau w P_{k=M}{ }^{-1}\left(1-\sum_{i} \mu_{l, i} \rho_{i}\right)\right. \\
& \left.-\frac{\tau}{1-\tau}\left(\sum_{i} \mu_{l, i} \rho_{i}\right) \sum_{i} \xi_{i}{ }^{-1} H_{0, i}{ }^{1+\beta_{i}}\right)
\end{aligned}
$$




\subsection{Solving the Model}

The model is difficult to solve analytically, but it can be arranged in such a way that is relatively straight-forward to solve numerically.

First, a numeraire must be chosen, and in this model the price of "other" goods $P_{k=O}$ is used for this purpose. From this, the production functions (3.16), and the perfect competition constraint (3.18), the price of healthcare goods $P_{k=M}$ is given by:

$$
P_{k=M}=\frac{P_{k=O} A_{k=O}}{A_{k=M}}
$$

The wage level $w$ and the ratio $\rho_{i}$ can then be solved using the following system of equations. Note that, if $w$ and $\rho_{i}$ are available and the equations are calculated in the order given, each equation is only dependent on parameters and previously-calculated variables.

\subsubsection{System of Equations for Solving}

Aggregate government provision of healthcare:

$$
\begin{aligned}
C_{k=M}^{G}=\left(1+\frac{\tau}{1-\tau} \sum_{i} \mu_{l, i} \rho_{i}\right)^{-1} & \left(n \tau w P_{k=M}{ }^{-1}\left(1-\sum_{i} \mu_{l, i} \rho_{i}\right)\right. \\
& \left.-\frac{\tau}{1-\tau}\left(\sum_{i} \mu_{l, i} \rho_{i}\right) \sum_{i} \xi_{i}{ }^{-1} H_{0, i}{ }^{1+\beta_{i}}\right)
\end{aligned}
$$


Government provision of healthcare to individuals (distribution of public healthcare):

$$
\begin{aligned}
C_{k=M, i}^{G}= & \rho_{i}\left(C_{k=M}^{G}+\sum_{i} \xi_{i}{ }^{-1} H_{0, i}{ }^{1+\beta_{i}}+(1-\tau) n w P_{k=M}{ }^{-1}\right) \\
& -(1-\tau) w P_{k=M}{ }^{-1}-\xi_{i}{ }^{-1} H_{0, i}{ }^{1+\beta_{i}}
\end{aligned}
$$

Individual purchases of healthcare:

$$
C_{k=M, i}^{I}=\mu_{H, i}(1-\tau) w P_{k=M}{ }^{-1}-\left(1-\mu_{H, i}\right)\left(C_{k=M, i}^{G}+\xi_{i}{ }^{-1} H_{0, i}{ }^{1+\beta_{i}}\right)
$$

Average (societal) level of health:

$$
H_{S}=n^{\frac{-1}{1-\gamma_{i}}}\left(\sum_{i} H_{0, i}+\sum_{i} \xi_{i} H_{0, i}{ }^{-\beta_{i}}\left(C_{k=M, i}^{I}+C_{k=M, i}^{G}\right)\right)^{\frac{1}{1-\gamma_{i}}}
$$

Individual level of health:

$$
H_{i}=H_{S}{ }^{\gamma_{i}}\left(H_{0, i}+\xi_{i} H_{0, i}{ }^{-\beta_{i}}\left(C_{k=M, i}^{I}+C_{k=M, i}^{G}\right)\right)
$$

Leisure:

$$
l_{i}=\mu_{l, i}\left[1+\frac{P_{k=M}}{(1-\tau) w}\left(C_{k=M, i}^{G}+\xi_{i}^{-1} H_{0, i}{ }^{1+\beta_{i}}\right)\right]
$$

Labour supply by individuals:

$$
L_{i}=1-l_{i}
$$


Production of goods by firms:

$$
Q_{k}=\sum_{i} C_{k, i}^{I}+C_{k}^{G}
$$

Individual purchases of other goods:

$$
C_{k=O, i}^{I}=\mu_{k=O, i}(1-\tau) w P_{k=O}{ }^{-1}\left[1+\frac{P_{k=M}}{(1-\tau) w}\left(C_{k=M, i}^{G}+\xi_{i}{ }^{-1} H_{0, i}{ }^{1+\beta_{i}}\right)\right]
$$

Individual after-tax income:

$$
Y_{i}=(1-\tau) w L_{i}
$$

Individual utility:

$$
U_{i}=H_{i}{ }^{\mu_{H, i}} l_{i}{ }^{\mu_{l, i}} C_{k=O, i}{ }^{\mu_{k=O, i}}
$$

Wages:

$$
w=\frac{\sum_{k} P_{k} Q_{k}}{\sum_{i} L_{i}}
$$


Ratio for public healthcare distribution:

$$
\rho_{i}=\left\{\begin{array}{cc}
\frac{\mu_{H, i} U_{i}{ }^{1-\nu}}{\sum_{i} \mu_{H, i} U_{i}{ }^{1-\nu}} & \text { for the utility objective } \\
\frac{H_{i}{ }^{1-\nu}}{\sum_{i} H_{i}{ }^{1-\nu}} & \text { for the health objective } \\
\frac{H_{i} Y_{i}{ }^{-\nu}\left(H_{S} \gamma_{i} \xi_{i} H_{0, i}-\beta_{i}\right.}{\sum^{-1}} & \text { for the income objective } \\
\sum_{i} H_{i} Y_{i}{ }^{-\nu}\left(H_{S}{ }^{\gamma} \xi_{i} H_{0, i}{ }^{-\beta_{i}}\right)^{-1} & \\
\sum_{i} H_{i} L_{i} & \text { for the GDP objective }
\end{array}\right.
$$

The remaining variables can be calculated from the variables solved in this system. 


\section{Chapter 4}

\section{Results}

Three different scenarios are calculated using the model for each of seven different government objectives that are considered. The government can choose to distribute healthcare to maximise GDP (one objective), or to maximise social welfare defined over utility, health, or after-tax income with either high (Rawlsian) or low (Benthamite) inequality aversion (six objectives). Governments also choose the tax rate and so (implicitly) the total level of public healthcare. For each of these objectives, model results are calculated for a homogeneous population, and for a health-heterogeneous population with and without a public health effect (i.e. three scenarios for each objective). These scenarios allow us to understand the effects of taxation, individual health-heterogeneity, public health, and inequality aversion under different government objectives.

For each scenario, the results are calculated for income taxes ranging in $1 \%$ increments from $0 \%$ to $30 \%$ (inclusive) for a society of two individualsone intrinsically "healthy" and one intrinsically "unhealthy". Taxation at 
$30 \%$ is the highest rate considered for several reasons. Remember that in this model, government income (which is solely from income tax) is only used for health. The USA spends by far the highest proportion of GDP on healthcare (public and private provision) at 17\% of GDP, and New Zealand is much more typical of OECD countries spending $9 \%$ of GDP on healthcare (OECD, 2017c). With the parameters used here (given in the Appendix), a $30 \%$ tax rate corresponds to public (excluding private) healthcare spending of about $30 \%$ of GDP - almost twice that of the public and private healthcare spending of the USA and three times that of a typical OECD country like New Zealand. In addition, at higher levels of taxation, markets in the model may no longer clear; and at still higher levels, individuals will choose not to work at all, preventing the model from solving.

The remainder of this chapter is arranged as follows. First is a discussion on the effect of taxes in the model. This section focusses on the results from the homogeneous population scenario, but most of the conclusions also apply to a heterogeneous population. Next, the results for when the government maximises social welfare defined over after-tax income (with a heterogeneous population) is considered. This government objective gives very different results to other government objectives and so is treated separately. Third, the results from all other government objectives with a heterogeneous population but no public health are described, then finally public health is also included. 


\subsection{The Effect of Taxes}

This section focusses on the effect of taxes when the individuals modelled are homogeneous. However, many of the results are qualitatively similar in populations of heterogeneous individuals, and the same explanations apply. Taxes have two competing effects in the model, shown diagrammatically in Figure 4.1. Firstly, higher taxes decrease the incentive to work and so labour supply decreases while leisure increases. The decrease in labour supply (along with the increase in taxes) reduces income, which leads to lower purchases of both "other" goods and "healthcare" goods. Because less healthcare goods are purchased, health decreases (ceteris paribus) as taxes increase (but never below the intrinsic health level), which then reduces the productivity of firms. Lower productivity leads to lower wages, which further decreases income and labour supply.

Secondly, however, the government income from taxation is spent on healthcare. Higher taxes increase the amount of healthcare the government can purchase and distribute to individuals. This increases the health of individuals, thereby increasing their productivity, increasing wages and the incentive to work, and decreasing leisure.

With a homogeneous population, there is no difference between the individuals that make up the society, and thus no inequality of any sort. Government therefore will distribute healthcare equally between the two individuals, irrespective of the choice rules used for distribution (provided these are not based on any criteria except differences between individuals). Thus, given the homogeneous population and given the parameters in the model, the dif- 


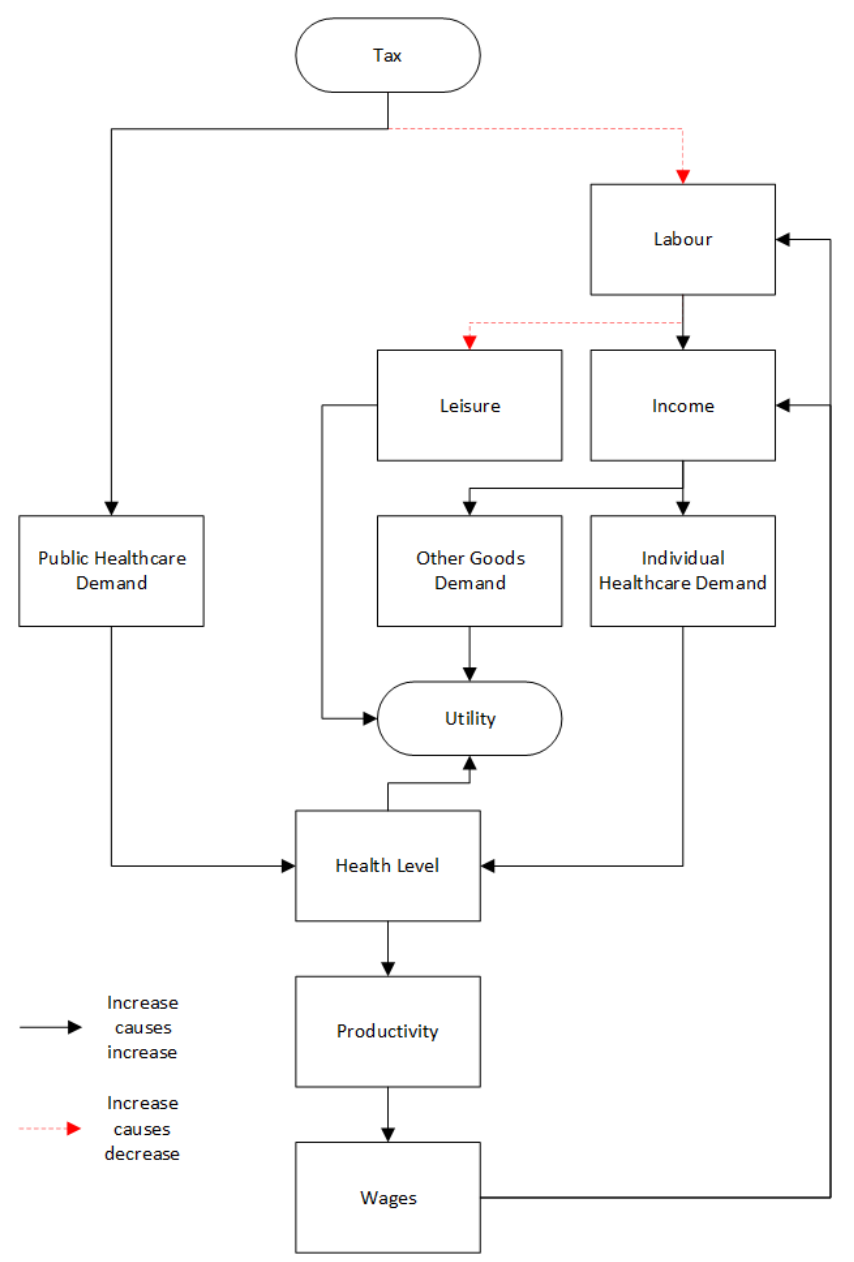

Figure 4.1: The effects of taxes

ferent objectives of the government have no effect on any variable; and for any given tax rate, the model has the same solution.

With the parameters used here, the decrease in the (homogeneous) individual's purchase of healthcare goods due to higher taxes is not matched by the increase in supply of public healthcare goods, and so health levels are reduced as taxes (all of which are spent on healthcare) increase. Income and purchases of other goods also decrease as taxes increase, so GDP also decreases. Leisure increases, but this is not generally enough to compensate for 
the reduction in health and consumption, so utility also decreases, as shown in Figure 4.2. This scenario illustrates the inefficiencies caused by an income $\operatorname{tax}$.

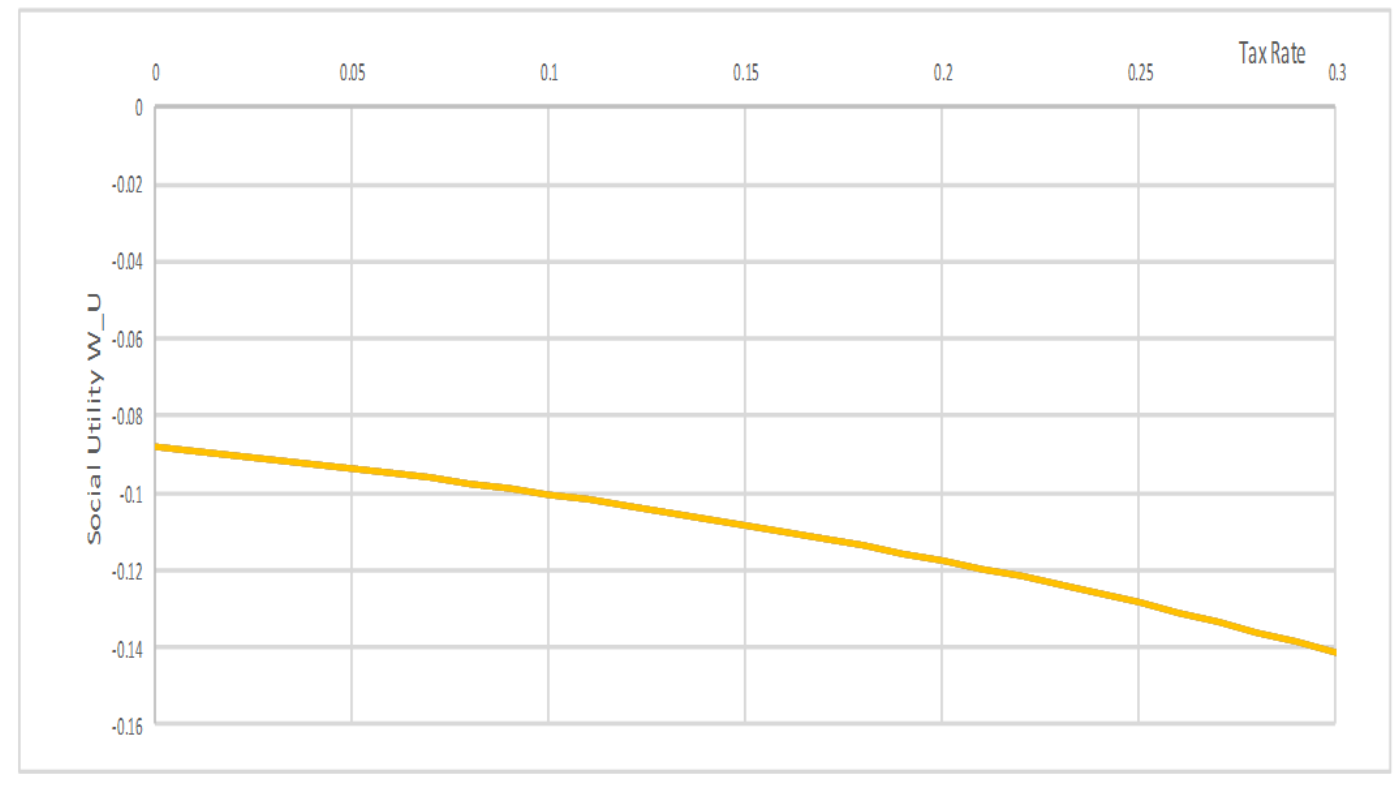

Figure 4.2: Social welfare with homogeneous individuals

In addition, when this model is run for higher tax rates $(>30 \%)$, a Laffer curve (Laffer, 2004) emerges, in which government income increases to a maximum and then declines. Government income increases as taxes increase, but individuals prefer to enjoy more leisure as taxes increase (as wages are effectively lower). Eventually, at very high tax rates, individuals chose not to work at all, reducing government income from taxation. 


\subsection{Maximising (Weighted) Individual After- Tax Income}

Most of the choices of government objectives give qualitatively similar results to each other as taxes change, but when a government aims to maximise the isoleastic function defined over individual after-tax income (with high or low inequality aversion), the response to increasing taxation is significantly different both to the responses from other objectives, and from what might be expected or desired. In brief, the results for every metric are worse than for other objectives, and the difference increases as taxes increase. To illustrate this result, Figure 4.3 graphs the outcomes for social welfare defined over utility (with low inequality aversion and no public health effect). Similar graphs can be drawn for the other scenarios, and for other metrics.

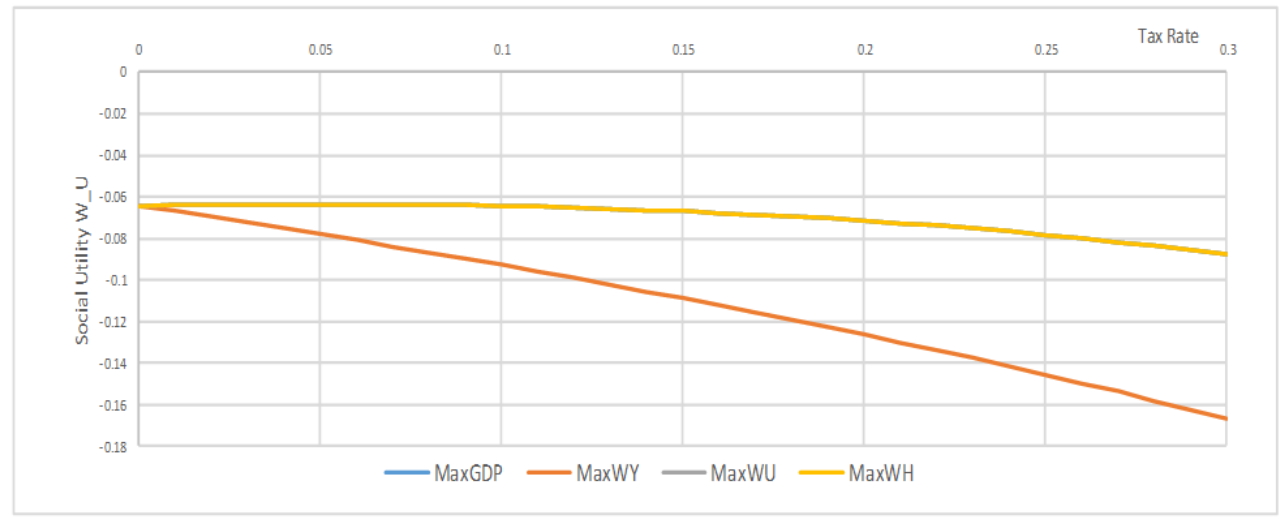

Figure 4.3: Social welfare defined over utility with heterogeneous individuals, low inequality aversion, and no public health. Note that the MaxGDP, MaxWU, and MaxWH curves are on top of each other.

Consider a healthy individual in this model. As they are already healthy, they do not need to buy large amounts of healthcare, and instead they choose to 
buy other goods and leisure. Thus, they work less than unhealthy individuals, who want to spend more of their income on healthcare. As wages are assumed to be the same for all individuals (regardless of health status), those who enjoy more leisure and so work less (i.e. healthy individuals) have lower incomes. However, the government tries to increase incomes by the way it distributes healthcare. It thus distributes more healthcare to those who work less and are already healthy, reducing their incentive to work both through the effect of taxes and through higher health; and lowering their income still further. This creates the perverse situation where healthy individuals are provided with more healthcare than unhealthy individuals, and after-tax incomes are reduced and made less equal. This situation is worse for higher taxes and greater inequality aversion.

As the (perverse) outcomes for these government objectives (maximising social welfare from after-tax income with high and low inequality aversion) have been discussed in detail in this section, they will not be discussed again in future sections, although results for them will be included alongside the results of the other government objectives.

\subsection{Optimal Tax Levels with Heterogeneous Individuals and No Public Health Effect}

Each of the government objectives other than maximisation of GDP involves maximising a social welfare function $W$ with a given level of inequality aversion $\nu$. The maximum for each social welfare function occurs at a different 
tax rate, and gives different results for individual health and utility. These results are given in Table 4.1 .

Table 4.1: Optimal results for each government objective with healthheterogeneous individuals but no public health effect

\begin{tabular}{lrrrrrrr} 
Maximise & $W_{U}$ & $W_{H}$ & $W_{Y}$ & $W_{U}$ & $W_{H}$ & $W_{Y}$ & $W_{G D P}$ \\
& $\nu=20$ & $\nu=20$ & $\nu=20$ & $\nu=0.01$ & $\nu=0.01$ & $\nu=0.01$ & \\
\hline$\tau$ & $18 \%$ & $4 \%$ & $0 \%$ & $5 \%$ & $0 \%$ & $0 \%$ & $0 \%$ \\
$W_{U}, \nu=0.01$ & -0.0694 & -0.0636 & -0.0642 & -0.0636 & -0.0642 & -0.0642 & -0.0642 \\
$W_{U}, \nu=20$ & -0.10 & -0.18 & -0.23 & -0.16 & -0.23 & -0.23 & -0.23 \\
$\mathrm{GDP}$ & 1.84 & 1.98 & 2.01 & 1.98 & 2.01 & 2.01 & 2.01 \\
$U_{i=\text { healthy }}$ & 0.97 & 1.01 & 1.02 & 1.01 & 1.02 & 1.02 & 1.02 \\
$U_{i=\text { unhealthy }}$ & 0.96 & 0.92 & 0.91 & 0.93 & 0.91 & 0.91 & 0.91 \\
$Y_{i=\text { healthy }}$ & 0.72 & 0.90 & 0.95 & 0.89 & 0.95 & 0.95 & 0.95 \\
$Y_{i=\text { unhealthy }}$ & 0.79 & 1.00 & 1.06 & 0.99 & 1.06 & 1.06 & 1.06 \\
$H_{i=\text { healthy }}$ & 1.27 & 1.35 & 1.37 & 1.34 & 1.37 & 1.37 & 1.37 \\
$H_{i=\text { unhealthy }}$ & 1.32 & 1.30 & 1.29 & 1.30 & 1.29 & 1.29 & 1.29 \\
$C_{k=M, i=h e a l t h y}^{G}$ & 0.00 & 0.00 & 0.00 & 0.00 & 0.00 & 0.00 & 0.00 \\
$C_{k=\text { M,i=unhealthy }}^{G}$ & 0.33 & 0.08 & 0.00 & 0.10 & 0.00 & 0.00 & 0.00 \\
$C_{k=M, i=h e a l t h y}^{I}$ & 0.37 & 0.54 & 0.58 & 0.52 & 0.58 & 0.58 & 0.58 \\
$C_{k=M, i=\text { unhealthy }}^{I}$ & 0.52 & 0.74 & 0.80 & 0.72 & 0.80 & 0.80 & 0.80 \\
$C_{k=\text { O,i=healthy }}^{I}$ & 0.35 & 0.37 & 0.37 & 0.37 & 0.37 & 0.37 & 0.37 \\
$C_{k=\text { O,i=unhealthy }}^{I}$ & 0.27 & 0.27 & 0.26 & 0.27 & 0.26 & 0.26 & 0.26 \\
$l_{i=\text { healthy }}$ & 0.33 & 0.29 & 0.28 & 0.29 & 0.28 & 0.28 & 0.28 \\
$l_{i=\text { unhealthy }}$ & 0.25 & 0.21 & 0.20 & 0.21 & 0.20 & 0.20 & 0.20
\end{tabular}

Consider first governments that have high inequality aversion $(\nu=20)$, and maximise social welfare from individual utility $W_{U}$. They will achieve the highest social welfare (measured assuming high inequality aversion) at a tax rate of $18 \%$. However, this does come at a cost to GDP (which registers the lowest value across all seven objectives).

As might be expected, this objective results in the most equal outcomes for utility, as the government has both high inequality aversion and high enough taxes to make a difference to inequality. Individual utility is nearly the same 
between individuals, and has a similar unweighted average (0.965) to other scenarios. After-tax income $Y_{i}$ is also much more equal, but due to the higher taxes is also much lower than other scenarios. As in all the cases, $Y_{i}$ is higher for the inherently unhealthy individual, as they choose to enjoy less leisure so they can afford to purchase more private healthcare. Inherently unhealthy individuals also receive more public healthcare. They thus receive substantially more healthcare than the intrinsically healthy individuals. Because of this, and because intrinsically unhealthy individuals get a larger benefit from healthcare, they end up with a higher health level than the intrinsically healthy individuals. Although average health level is lowest for this objective, the health of the intrinsically unhealthy individual is highest for this objective. The health of the intrinsically healthy individual is lower than the health of any individual (healthy or unhealthy) for any other objective. In all cases, other consumption is higher for the intrinsically healthy individuals than intrinsically unhealthy individuals as they do not need to spend as much of their income on healthcare to reach a given health level.

Now consider governments that have low inequality aversion $(\nu=0.01)$ and maximise social welfare from individual utility $W_{U}$. They will achieve the highest social welfare (measured assuming low inequality aversion) at a tax rate of $5 \%$, although the difference in this measure of social welfare across different tax rates is small. The cost to GDP is much lower for this objective, as would be expected with the lower tax rate. Individual utility is less equal than with the high inequality aversion objective (as would be expected), but health is more equal and average health is higher. This is because, with the lower taxation, there is less deadweight losses, and more healthcare can be 
produced. The intrinsically healthy individuals receive as much healthcare in total as the intrinsically unhealthy individuals did in the high inequality case above, and the intrinsically unhealthy individuals receive somewhat more; but not quite enough to catch up to the health level of the intrinsicallyhealthy individuals. Individuals facing this government objective work more (due to the lower taxes) and so have less leisure, but purchase slightly more other goods than those facing the high inequality aversion government objective.

A government that has high inequality aversion and maximises social welfare defined over health will achieve its optimum at a tax rate of $4 \%$, with very similar results to a government with low inequality aversion that maximises social welfare from utility. All other government objectives are best met at a $0 \%$ tax rate, which, as the laissez-faire situation, means there will be no public provision of healthcare. These results are illustrated in Figures 4.4-4.6.

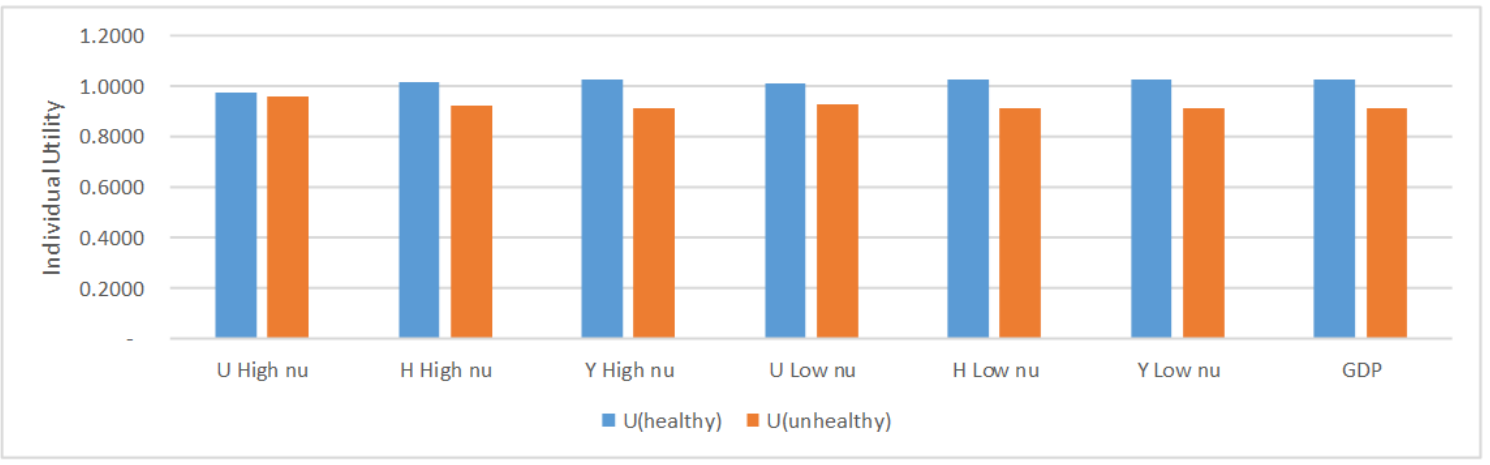

Figure 4.4: Individual utility for different government objectives 


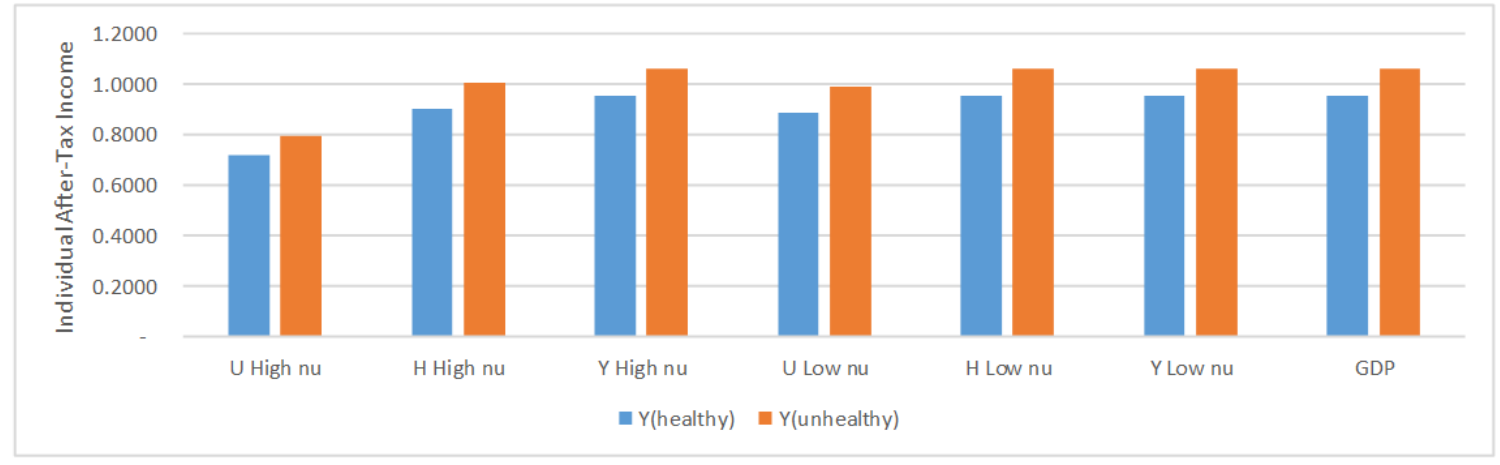

Figure 4.5: Individual after-tax income for different government objectives

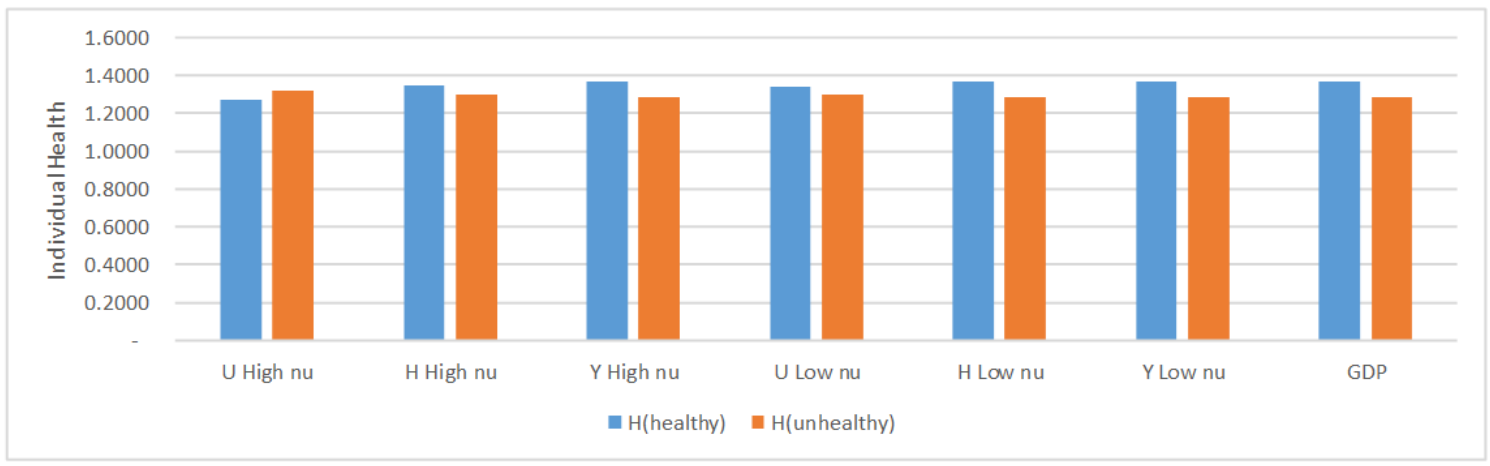

Figure 4.6: Individual health for different government objectives

\subsection{Optimal Tax Levels with Heterogeneous Individuals and Public Health Effect}

Each of the government objectives requires maximisation of a social welfare function with a given level of inequality aversion. In this section, we also include the effect of public health. The maximum for each social welfare function may occur at a different tax rate, and gives different results for individual health and utility. These results are given in Table 4.2.

Including the effect of public health on individual health levels generally re- 
Table 4.2: Optimal results for each government objective with healthheterogeneous individuals and public health effects

\begin{tabular}{lrrrrrrr} 
& Maximise & & & & & & \\
& $W_{U}$ & $W_{H}$ & $W_{Y}$ & $W_{U}$ & $W_{H}$ & $W_{Y}$ & $W_{G D P}$ \\
& $\nu=20$ & $\nu=20$ & $\nu=20$ & $\nu=0.01$ & $\nu=0.01$ & $\nu=0.01$ & \\
\hline$\tau$ & $7 \%$ & $0 \%$ & $0 \%$ & $0 \%$ & $0 \%$ & $0 \%$ & $0 \%$ \\
$W_{U}, \nu=0.01$ & 0.336 & 0.346 & 0.346 & 0.346 & 0.346 & 0.346 & 0.346 \\
$W_{U}, \nu=20$ & 0.0995 & 0.0986 & 0.0986 & 0.0986 & 0.0986 & 0.0986 & 0.0986 \\
GDP & 2.59 & 2.68 & 2.68 & 2.68 & 2.68 & 2.68 & 2.68 \\
$U_{i=\text { healthy }}$ & 1.19 & 1.22 & 1.22 & 1.22 & 1.22 & 1.22 & 1.22 \\
$U_{i=\text { unhealthy }}$ & 1.15 & 1.13 & 1.13 & 1.13 & 1.13 & 1.13 & 1.13 \\
$Y_{i=\text { healthy }}$ & 1.16 & 1.28 & 1.28 & 1.28 & 1.28 & 1.28 & 1.28 \\
$Y_{i=\text { unhealthy }}$ & 1.25 & 1.39 & 1.39 & 1.39 & 1.39 & 1.39 & 1.39 \\
$H_{i=\text { healthy }}$ & 1.65 & 1.71 & 1.71 & 1.71 & 1.71 & 1.71 & 1.71 \\
$H_{i=\text { unhealthy }}$ & 1.69 & 1.67 & 1.67 & 1.67 & 1.67 & 1.67 & 1.67 \\
$C_{k=M, i=h e a l t h y}^{G}$ & 0.00 & 0.00 & 0.00 & 0.00 & 0.00 & 0.00 & 0.00 \\
$C_{k=M, i=\text { unhealthy }}^{G}$ & 0.18 & 0.00 & 0.00 & 0.00 & 0.00 & 0.00 & 0.00 \\
$C_{k=\text { M,i=healthy }}^{I}$ & 0.76 & 0.87 & 0.87 & 0.87 & 0.87 & 0.87 & 0.87 \\
$C_{k=M, i=\text { unhealthy }}^{I}$ & 0.95 & 1.09 & 1.09 & 1.09 & 1.09 & 1.09 & 1.09 \\
$C_{k=\text { O,i=healthy }}^{I}$ & 0.40 & 0.41 & 0.41 & 0.41 & 0.41 & 0.41 & 0.41 \\
$C_{k=\text { O,i=unhealthy }}^{I}$ & 0.30 & 0.30 & 0.30 & 0.30 & 0.30 & 0.30 & 0.30 \\
$l_{i=\text { healthy }}$ & 0.25 & 0.24 & 0.24 & 0.24 & 0.24 & 0.24 & 0.24 \\
$l_{i=\text { unhealthy }}$ & 0.20 & 0.18 & 0.18 & 0.18 & 0.18 & 0.18 & 0.18
\end{tabular}

duces the optimal level of taxes for all government objectives. This is due to the higher level of health in this society induced by positive public health externalities. When $H_{S}<1$, the public health externalities will reduce the health level of individuals, but when $H_{S}>1$ they increase the health level of individuals (see equation (3.4)). For this society (i.e. for the assumed parameters in the model), although the average level of intrinsic health is 0.95 (i.e. below 1), individuals purchase enough healthcare to bring average health $H_{S}$ above 1 even when the government does not provide any healthcare. Thus, including public health effects increases overall health levels and reduces the marginal contribution of government provision of healthcare. 
When including a public health effect, the optimal tax rate for most government objectives is $0 \%$. The one exception is a high-inequality-aversion government that maximises social welfare from utility, which has an optimal tax rate of $7 \%$ (without public health, this objective also results in the highest tax rate of all objectives). As in the no-public-health scenario, GDP is slightly lower, individual utility is more equal, and incomes are lower than with other government objectives. Intrinsically unhealthy individuals end up with higher health levels than intrinsically healthy individuals, as well as more income but less leisure and other goods. These differences are explained in the same way as before, with the intrinsically-unhealthy individuals receiving more healthcare and getting greater benefit from it than the intrinsically-healthy individuals, so ending up with higher health levels. 


\section{Chapter 5}

\section{Conclusion}

This work has investigated the optimal role for government in healthcare provision with four complicating factors:

- Individual heterogeneity of intrinsic health

- Externalities of health levels

- Imperfect information held by firms and government agents about individuals

- A range of different government objectives

The analysis has involved developing and solving a model that helps us to understand the way health, income, consumption, and wellbeing interact with each other and with the provision of healthcare services by the government and the private sector.

Introducing individual heterogeneity of intrinsic health makes the choice of government allocation of healthcare important. Without heterogeneity, the 
best tax rate on all measures of wellbeing used in this model is $0 \%$, i.e. the laissez-faire solution is optimal.

Introducing public health as an externality increases health levels with the parameters used here, and this results in lower optimal tax rates for all government objectives than in a model without this externality. As individual health is higher, both the desire for and effectiveness of healthcare are reduced; and therefore the value of government provision of healthcare is lower.

As it is assumed that firms cannot use the health of individuals in setting wages, higher-health individuals tend to enjoy more leisure, but have lower incomes as a result. This is likely to change if firms can pay individuals differently based on their productivity, as healthier individuals are more productive in this model.

If governments do not have information about individual utilities or preferences (as is likely), they are unable to distribute healthcare optimally. In that case they would have to resort to maximisation of an objective based on observables; five possibilities are included in the analysis (based on after-tax income, health, and GDP).

When governments maximise social utility defined over after-tax income, particularly if they have high inequality aversion, any increase in tax rates causes a significant decline in measured social utility (and other measures of interest). This is due to the perverse situation where households with high intrinsic health receive more healthcare as they have lower incomes through choosing to enjoy greater leisure. 
For the other government objectives studied here, namely maximising GDP, social welfare defined over health, as well as social welfare defined over utility, social utility changes as tax rates change. The highest optimal tax rates are obtained for governments with high inequality aversion that maximise social welfare from utility. In this case (unlike for other government objectives), the ultimate health level of the intrinsically unhealthy individual is higher than that of the intrinsically healthy individual, due to much higher healthcare provision, which is also assumed to be more effective for individuals with lower intrinsic health levels.

Thus, based on this model, governments can increase measured social welfare from utility by taxing individuals to provide public healthcare, particularly if they have high inequality aversion. If their citizens enjoy good public health, this will reduce the optimal level of taxation. Distributing healthcare to maximise GDP or social welfare from health are other proxies, but they result in lower social welfare (defined over utility).

The analysis in this work has only investigated a limited range of the possibilities in this model. A richer set of conclusions could be obtained by testing a wider range of the parameters, and by increasing the number of individuals, perhaps as a microsimulation exercise. In particular, it would be useful to confirm (using a range of parameters within the model) that poor public health leads to lower overall wellbeing, and to see how provision of public healthcare affected that result.

There are also many possible and interesting extensions to the model itself (although increasing the complexity of the model also reduces the clarity 
and interpretability of the results). Individuals might make different choices about their healthcare if firms could set wages based on health levels. They might also make different choices, perhaps choosing not to take up some public provision of healthcare, if it requires some time input on their part. The effect of leisure and of wellbeing on health has not been incorporated either. Finally, this model is a static model, but in reality individuals live in a dynamic world, making intertemporal trade-offs, and experiencing different levels of intrinsic health at different ages; and this model abstracts from these dynamics. However, this simple model allows us to show how health-heterogeneous populations and public health externalities affect the optimal choice of public provision of healthcare, as do different government objectives. These contributions have not hitherto been incorporated into a single optimising model so the results contribute new understanding to the interactions of healthcare policy, taxes, and optimal public policy. 


\section{Bibliography}

Abdallah, Saamah et al. (2009). The Happy Planet Index 2.0: Why good lives don't have to cost the Earth. New Economics Foundation.

Acemoglu, Daron et al. (2016). "Transition to Clean Technology". In: Journal of Political Economy 124.1, pp. 52-104. URL: http://www.jstor.org/ action/showPublication?journalCode=jpoliecon.

Alkire, Sabina (2002). "Dimensions of Human Development". In: World Development 30.2, pp. 181-205. URL: http: //www. sciencedirect.com/ science/ARTICLE/pii/S0305750X01001097.

Arrow, Kenneth J. et al. (2012). "Sustainability and the measurement of wealth". In: Environment and Development Economics 17.03, pp. 317353. URL: http://www.niesr.ac.uk/pdf/161110_134451.pdf.

- (2013). "Sustainability and the measurement of wealth: further reflections." In: Environment and Development Economics 18.04, pp. 504-516. URL: https : / /ideas . repec . org/a / cup/endeec/v18y2013i04p504516_00.html.

Atkinson, Anthony B and Joseph E Stiglitz (1980). Lectures on Public Economics. Economics Handbook Series. New York: McGraw-Hill. 
Becchetti, Leonardo et al. (2013). "Beyond the Joneses: Inter-country income comparisons and happiness." In: Journal of Socio-Economics 45, pp. 187195.

Bentham, Jeremy (1789). An Introduction to the Principles of Morals and Legislation. Printed in the Year 1780, and Now First Published. By Jeremy Bentham,..... T. Payne, and Son.

Danner, Deborah D., David A. Snowdon, and Wallace V. Friesen (2001). "Positive Emotions in Early Life and Longevity: Findings from the Nun Study." In: Journal of Personality and Social Psychology 80.5, pp. 804813.

Dasgupta, Partha and Geoffrey Heal (1974). "The Optimal Depletion of Exhaustible Resources". In: The Review of Economic Studies 41, pp. 3-28. URL: http://www.jstor.org/stable/2296369.

Easterlin, Richard A. (1974). "Does economic growth improve the human lot? : some empirical evidence." In: Nations and households in economic growth: essays in honor of Moses Abramovitz. Ed. by Paul A. David and Melvin W. Reder. New York: Academic Press, Inc., pp. 89-125. URL: http : / / graphics8 . nytimes . com/images / 2008/04/16/business / Easterlin1974.pdf.

Easterlin, Richard A. et al. (2010). "The happiness-income paradox revisited". In: Proceedings of the National Academy of Sciences of the United States of America 107.52, pp. 22463-22468. URL: http: //www . jstor . org/stable/25770662.

Fleurbaey, Marc (2005). "Health, Wealth, and Fairness". In: Journal of Public Economic Theory 7.2, pp. 253-284. 
Gleisner, Ben, Mary Llewellyn-Fowler, and Fiona McAlister (2011). Working Towards Higher Living Standards for New Zealanders. Treasury Paper 11/02. New Zealand Treasury. URL: http://www.treasury.govt.nz/ publications/research-policy/tp/higherlivingstandards.

Greasley, David et al. (2014). "Testing genuine savings as a forward-looking indicator of future well-being over the (very) long-run". In: Journal of Environmental Economics and Management 67.2, pp. 171-188. URL: http: //wWw.sciencedirect.com/science/ARTICLE/pii/S0095069613001083.

Grimes, Arthur and Marc Reinhardt (2015). Relative Income and Subjective Wellbeing: Intra-national and Inter-national Comparisons by Settlement and Country Type. Motu Working Paper 15-10. Wellington: Motu. URL: http://motu-www.motu.org.nz/wpapers/15_10.pdf.

Grossman, Michael (1972). "On the Concept of Health Capital and the Demand for Health". In: Journal of Political Economy 80.2, pp. 223-55. URL: https://ideas.repec.org/a/ucp/jpolec/v80y1972i2p223-55.html.

Hamilton, Kirk (2000). Genuine Saving as a Sustainability Indicator. Environment Department papers 77. World Bank, pp. 65-78. URL: https : //openknowledge. worldbank . org/handle/10986/18301.

Harsanyi, John C (1977). Rational Behaviour and Bargaining Equilibrium in Games and Social Situations. Cambridge University Press.

Helliwell, John F., Richard Layard, and Jeffrey D Sachs (2015). "Setting the Stage". In: World Happiness Report 2015. Ed. by John F. Helliwell, Richard Layard, and Jeffrey D Sachs. New York: Sustainable Development Solutions Network, pp. 1-11. URL: http://worldhappiness .report/wpcontent/uploads/sites/2/2015/04/WHR15_Sep15.pdf. 
Karacaoglu, Girol (2015). The New Zealand Treasury's Living Standards Framework - Exploring a Stylised Model. Working Paper 15/12. New Zealand Treasury. URL: http://www.treasury.govt.nz/publications/ research-policy/wp/2015/15-12/.

King, Anita (2018). Living Standards Analysis Model: The First Prototype. Working Paper forthcoming. New Zealand Treasury.

King, Anita, Gulnara Huseynli, and Nairn MacGibbon (2018). Wellbeing Frameworks for the Treasury. Discussion Paper 18/01. New Zealand Treasury. URL: https://treasury.govt.nz/publications/dp/wellbeingframeworks-treasury-dp-18-01.

Krawczyk, Jacek B. et al. (2013). "Computation of viability kernels: a case study of by-catch fisheries". In: Computational Management Science 10.4, pp. 365-396.

Kuznets, Simon (1934). "National Income, 1929-1932. 73rd US Congress, 2nd Session, Senate Document No. 124". In: United States Congress Washington, DC. URL: https://fraser.stlouisfed.org/scribd/?title_ id $=971 \&$ filepath $=/$ files $/$ docs / publications / natincome_ $1934 /$ 19340104_nationalinc.pdf (visited on 12/20/2017).

Laffer, Arthur B (2004). "The Laffer curve: Past, present, and future". In: Backgrounder 1765, pp. 1-16. URL: http://www . nmhd28gop.org/wpcontent/uploads/2017/10/bg1765.pdf

Layard, Richard (2005). Happiness: Lessons from a new science. Penguin UK. 
Lucas, Richard (2016). "Subjective Well-being in Psychology". In: The $O x$ ford Handbook of Well-Being and Public Policy. Ed. by Matthew D. Adler and Marc Fleurbaey. Oxford University Press. Chap. 14, pp. 403-423.

Nordhaus, William D and James Tobin (1972). "Is Growth Obsolete?" In: Economic Research: Retrospect and Prospect, Volume 5, Economic Growth. NBER, pp. 1-80. URL: http://www.nber.org/chapters/c7620.pdf.

Nozick, Robert (1974). Anarchy, Utopia and State. Basil Blackwell, Oxford. Odermatt, Reto and Alois Stutzer (2017). Subjective Well-Being and Public Policy. Discussion Paper Series 11102. IZA Institute of Labor Economics. URL: http://ftp.iza.org/dp11102.pdf.

OECD (2011). "How's Life?: Measuring Well-being". In: DOI: http://dx . doi.org/10.1787/9789264121164-en.

- (2017a). Better Life Index. URL: http://wWw . oecdbetterlifeindex. org/\#/11111111111 (visited on 09/22/2017).

- (2017b). "Measuring Distance to the SDG Targets: an assessment of where OECD countries stand". In: URL: http ://www . oecd.org/std/ measuring-distance-to-the-sdgs-targets.htm.

- (2017c). OECD.Stat Health expenditure and financing. URL: http : / / stats.oecd.org/ (visited on 04/14/2018).

Rawls, John (1971). A theory of justice. Cambridge, MA: Harvard University Press.

Rijpma, Auke et al. (2017). Netherlands beyond GDP: A Wellbeing Index. MPRA Paper 78934. URL: https://mpra.ub.uni-muenchen.de/78934/ 1/MPRA_paper_78934.pdf. 
Robbins, Lionel (1932). An essay on the nature and significance of economic science. Macmillian. URL: https ://books . google.co.nz/books?hl= en\& $I r=\& i d=$ nySoIkOgWQ4C\&oi $=f n d \& p g=P A 1 \& d q=a n+$ essay $+o n+$ the + nature+and+significance + of + economic + science\&ots $=$ bwE $4 x W b r a z \&$ sig $=$ Bz9TxixRVmoxkWOPyONM5gstrJA \# v = onepage \& q = an \% 20essay $\%$ 20 on $\% 20$ the $\% 20$ nature $\% 20$ and $\% 20$ significance $\% 20$ of $\% 20$ economic $\%$ 20 science\&f $=f a l s e$.

Samuelson, P. A. (1938). "A Note on the Pure Theory of Consumer's Behaviour". In: Economica 17, pp. 61-71. URL: http://www.jstor .org/ stable/2548836?origin=crossref.

SDSN (2015). Indicators and a Monitoring Framework for the Sustainable Development Goals. UN Sustainable Development Solutions Network. URL: https : / / sustainabledevelopment . un .org/index . php? page=view \& type $=400 \& n r=2013 \&$ menu $=35$.

Sen, Amartya (1999). Development as freedom. Oxford: Oxford University Press.

- (2009). The idea of justice. Allen Lane.

Slesnick, Daniel T. (1989). "Specific Egalitarianism and Total Welfare Inequality: A Decompositional Analysis". In: The Review of Economics and Statistics 71.1, pp. 116-127.

Sridhar, Devi (2016). "Making the SDGs useful: a Herculean task". In: The Lancet 388.10053, pp. 1453-1454. URL: http://thelancet.com/pdfs / journals/lancet/PIIS0140-6736(16)31635-X.pdf.

Stevenson, Betsey and Justin Wolfers (2008). "Economic Growth and Subjective Well-Being: Reassessing the Easterlin Paradox". In: Brookings Pa- 
pers on Economic Activity, pp. 1-35. URL: http://go galegroup . $\mathrm{com} / \mathrm{ps} /$ retrieve $\cdot$ do $?$ tabID $=$ T002\& resultListType $=$ RESULT_LIST \& searchResultsType $=$ SingleTab \& searchType = AdvancedSearchForm \& currentPosition $=1 \&$ docId $=$ GALE $\%$ 7CA188998009\&docType=Article \& sort $=$ RELEVANCE\& contentSegment $=\&$ prod $I d=A O N E \&$ contentSet $=G A L E \%$ 7CA188998009\&searchId=R1\&userGroupName=per_tre\&inPS=true.

Stiglitz, Joseph, Amartya Sen, and Jean-Paul Fitoussi (2009). Report by the Commission on the Measurement of Economic Performance and Social Progress. Report. Commission on the Measurement of Economic Performance and Social Progress. URL: http : / / ec . europa . eu/eurostat / documents/118025/118123/Fitoussi+Commission+report.

The Legatum Institute (2016). The Legatum Prosperity Index 2016 Methodology Report. URL: http://www.prosperity.com/download_file/view/ 2885/1690 (visited on 09/22/2017).

Tobin, James (1970). "On Limiting the Domain of Inequality." In: The Journal of Law and Economics 13.2, pp. 263-277. URL: https://www. jstor . org/stable/725025.

UN (2008). System of National Accounts. United Nations Statistics Division. URL: https://unstats . un .org/unsd/nationalaccount/sna2008.asp.

- (2015). Transforming our World: the 2030 Agenda for Sustainable Development. Working Papers id:7559. eSocialSciences. URL: https : / / sustainabledevelopment . un.org/post2015/transformingourworld/ publication. 
UNDP (1990). Human Development Report 1990: Concept and Measurement of Human Development. United Nations Development Programme. URL: http://hdr. undp.org/en/reports/global/hdr1990.

- (2016). Human Development Report 2016: Human Development for Everyone. United Nations Development Programme. URL: http://hdr . undp.org/en/2016-report/download.

Waring, Marilyn and Gloria Steinem (1988). Counting for Nothing: what men value and what women are worth. Wellington: Allen \& Unwin/Port Nicholson Press. 


\section{Appendix A}

\section{Notation}

\section{A.1 Model Variables}

\begin{tabular}{ll} 
Variable & Description \\
\hline$C_{k, i}$ & Consumption level of good $k$ by individual $i$ \\
$C_{k}^{G}$ & Purchase (for consumption) of good $k$ by government \\
$C_{k, i}^{G}$ & Purchase for consumption by individual $i$ of good $k$ by gov- \\
& ernment \\
$C_{k, i}^{I}$ & Purchase by individual $i$ for consumption by individual $i$ of \\
& good $k$ \\
$H_{i}$ & Health level of individual $i$ (after healthcare) \\
$H_{S}$ & Average health of all individuals \\
$l_{i}$ & Leisure time for individual $i$ \\
$L_{i}$ & Time spent in paid labour for individual $i$ \\
$L_{k, i}$ & Time spent in paid labour for good $k$ by individual $i$ \\
$P_{k}$ & Price of produced good $k$
\end{tabular}




\begin{tabular}{ll} 
Variable & Description \\
\hline$Q_{k}$ & Quantity of production of good $k$ \\
$U_{i}$ & Utility level of individual $i$ \\
$w$ & Wages paid for the labour of any individual \\
$W_{G D P}$ & Social welfare based on GDP \\
$W_{H}$ & Social welfare based on health \\
$W_{U}$ & Social welfare based on individual utility \\
$W_{Y}$ & Social welfare based on individual after-tax income \\
$Y_{G}$ & Government income from taxes \\
$Y_{i}$ & After-tax income for individual $i$
\end{tabular}

\section{A.2 Model Parameters}

\begin{tabular}{lll} 
Parameter & Model Value & Description \\
\hline$A_{k}$ & $1 \forall k$ & $\begin{array}{l}\text { Multi-factor productivity for produc- } \\
\text { tion of good } k\end{array}$ \\
$H_{0, i}$ & $0.95 \forall i$ or $\{1.1,0.8\}$ & Intrinsic health level of individual $i$ (be- \\
& & fore healthcare) \\
$n$ & 2 & Number of individuals in the popula- \\
& & tion \\
$\beta_{i}$ & $0.9 \forall i$ & Effect of intrinsic health level improve- \\
& & ment from healthcare \\
$\gamma_{i}$ & 0 or $0.5, \forall i$ & Strength of public health externality \\
$\xi_{i}$ & $0.5 \forall i$ & Ability of individual $i$ to take advantage \\
& & of healthcare
\end{tabular}




\begin{tabular}{lll} 
Parameter & Model Value & Description \\
\hline$\mu_{H, i}$ & $0.8 \forall i$ & Parameter on health in Cobb-Douglas \\
& & utility function of individual $i$ \\
$\mu_{k=O, i}$ & $0.1 \forall i$ & Parameter on non-healthcare consump- \\
& & tion in Cobb-Douglas utility function of \\
& & individual $i$ \\
$\mu_{l, i}$ & $0.1 \forall i$ & Parameter on leisure for utility in \\
& & Cobb-Douglas utility function of indi- \\
& & vidual $i$ \\
$\nu$ & 0.01 or 20 & Level of inequality aversion \\
$\tau$ & {$[0,0.3]$} & Rate of tax on (labour) income
\end{tabular}




\section{Appendix B}

\section{Derivations}

\section{B.1 Useful Identities}

It is useful for the purposes of this model to note that GDP can be written in several equivalent forms:

$$
\begin{aligned}
W_{G D P} & =\sum_{k} P_{k} Q_{k} \\
& =\sum_{k} P_{k} \sum_{i} C_{k, i} \\
& =\sum_{k} P_{k} \sum_{i} C_{k, i}^{I}+\sum_{k} P_{k} \sum_{i} C_{k, i}^{G} \\
& =\sum_{i} \sum_{k} P_{k} C_{k, i}^{I}+\sum_{k} P_{k} C_{k}^{G} \\
& =(1-\tau) w \sum_{i} L_{i}+\tau w \sum_{i} L_{i} \\
W_{G D P}=\sum_{k} P_{k} Q_{k} & =w \sum_{i} L_{i}
\end{aligned}
$$


Starting with the income definition of GDP:

$$
\begin{aligned}
W_{G D P} & =w \sum_{i} L_{i} \\
\tau W_{G D P} & =\tau w \sum_{i} L_{i} \\
& =P_{k=M} C_{k=M}^{G}
\end{aligned}
$$

Starting with the perfect competition constraint:

$$
\begin{aligned}
& P_{k} Q_{k}=w \sum_{i} L_{i} \\
& =w \sum_{i}\left(\frac{L_{i} L_{k}}{\sum_{i} H_{i} L_{i}}\right) \\
& =\frac{w \sum_{i} L_{i}}{\sum_{i} H_{i} L_{i}} L_{k} \\
& L_{k}=\frac{\sum_{i} H_{i} L_{i}}{w \sum_{i} L_{i}} P_{k} Q_{k} \\
& =\frac{P_{k} Q_{k}}{\sum_{k} P_{k} Q_{k}} \sum_{i} H_{i} L_{i} \\
& \sum_{k} L_{k}=\frac{\sum_{k} P_{k} Q_{k}}{\sum_{k} P_{k} Q_{k}} \sum_{i} H_{i} L_{i} \\
& =\sum_{i} H_{i} L_{i}
\end{aligned}
$$




\section{B.2 Maximise Utility for Individuals}

Individual utility is given by:

$$
U_{i}=U_{i}\left(H_{i}, l_{i}, C_{k=O, i}\right)
$$

and is subject to the budget constraint and the definition of societal health. Thus the Lagrangian to maximise utility is given by:

$$
\begin{aligned}
\mathcal{L}_{i}= & U_{i}\left(H_{i}, l_{i}, C_{k=O, i}\right) \\
& +\lambda_{i}\left((1-\tau) w L_{i}\left(l_{i}\right)-\sum_{k} P_{k} C_{k, i}^{I}\left(H_{i}\right)\right)
\end{aligned}
$$

The first order conditions are given by:

$$
\begin{aligned}
0= & \frac{\partial \mathcal{L}_{i}}{\partial H_{i}} \\
= & \frac{\partial U_{i}}{\partial H_{i}}-\lambda_{i} P_{k=M} \frac{\partial C_{k=M, i}^{I}}{\partial H_{i}} \\
0= & \frac{\partial \mathcal{L}_{i}}{\partial l_{i}} \\
= & \frac{\partial U_{i}}{\partial l_{i}}+\lambda_{i}(1-\tau) w \frac{\partial L_{i}}{\partial l_{i}} \\
0 & =\frac{\partial \mathcal{L}_{i}}{\partial C_{k=O, i}^{I}} \\
& =\frac{\partial U_{i}}{\partial C_{k=O, i}}-\lambda_{i} P_{k=O}
\end{aligned}
$$


and the budget constraint

$$
\begin{aligned}
0 & =\frac{\partial \mathcal{L}_{i}}{\partial \lambda_{i}} \\
& =(1-\tau) w L_{i}\left(l_{i}\right)-\sum_{k} P_{k} C_{k, i}^{I}\left(H_{i}\right)
\end{aligned}
$$

Labour is given by

$$
L_{i}=1-l_{i}
$$

and so

$$
\frac{\partial L_{i}}{\partial l_{i}}=-1
$$

Healthcare purchased by individuals is given by:

$$
\begin{aligned}
H_{i} & =H_{S}{ }^{\gamma_{i}}\left(H_{0, i}+\xi_{i} H_{0, i}{ }^{-\beta_{i}}\left(C_{k=M, i}^{G}+C_{k=M, i}^{I}\right)\right) \\
C_{k=M, i}^{I} & =\frac{H_{i}-H_{S}^{\gamma_{i}}\left(H_{0, i}+\xi_{i} H_{0, i}{ }^{-\beta_{i}} C_{k=M, i}^{G}\right)}{H_{S}{ }^{\gamma_{i}} \xi_{i} H_{0, i}{ }^{-\beta_{i}}}
\end{aligned}
$$

and so

$$
\frac{\partial C_{k=M, i}^{I}}{\partial H_{i}}=\left(H_{S}{ }^{\gamma_{i}} \xi_{i} H_{0, i}{ }^{-\beta_{i}}\right)^{-1}
$$

Utility is given by:

$$
U_{i}=H_{i}{ }^{\mu_{H, i}} l_{i}{ }^{\mu_{l, i}} C_{k=O, i}{ }^{\mu_{k=O, i}}
$$


and so

$$
\begin{aligned}
\frac{\partial U_{i}}{\partial H_{i}} & =\mu_{H, i} H_{i}{ }^{{ }_{H, i}-1} l_{i}{ }^{\mu_{l, i}} C_{k=O, i}{ }^{\mu_{k=O, i}} \\
& =\mu_{H, i} H_{i}{ }^{-1} U_{i} \\
\frac{\partial U_{i}}{\partial l_{i}} & =\mu_{l, i} H_{i}{ }^{\mu_{H, i}} l_{i}{ }^{\mu_{l, i}-1} C_{k=O, i}{ }^{\mu_{k=O, i}} \\
& =\mu_{l, i} l_{i}{ }^{-1} U_{i} \\
\frac{\partial U_{i}}{\partial C_{k=O, i}} & =\mu_{k=O, i} H_{i}{ }^{\mu_{H, i}} l_{i}{ }^{\mu_{l, i}} C_{k=O, i}{ }^{\mu_{k=O, i}-1} \\
& =\mu_{k=O, i} C_{k=O, i}{ }^{-1} U_{i}
\end{aligned}
$$

The first order condition for health therefore becomes:

$$
\begin{aligned}
0 & =\mu_{H, i} H_{i}{ }^{-1} U_{i}-\lambda_{i} P_{k=M}\left(H_{S}{ }^{\gamma_{i}} \xi_{i} H_{0, i}{ }^{-\beta_{i}}\right)^{-1} \\
\mu_{H, i} U_{i} & =\lambda_{i} P_{k=M} H_{i}\left(H_{S}{ }^{\gamma_{i}} \xi_{i} H_{0, i}{ }^{-\beta_{i}}\right)^{-1} \\
& =\lambda_{i}\left[\frac{P_{k=M}\left(H_{0, i}+\xi_{i} H_{0, i}{ }^{-\beta_{i}}\left(C_{k=M, i}^{G}+C_{k=M, i}^{I}\right)\right)}{\xi_{i} H_{0, i}{ }^{-\beta_{i}}}\right] \\
& =\lambda_{i}\left[P_{k=M} \xi_{i}{ }^{-1} H_{0, i}{ }^{1+\beta_{i}}+P_{k=M} C_{k=M, i}^{G}+P_{k=M} C_{k=M, i}^{I}\right]
\end{aligned}
$$

The first order condition for leisure becomes:

$$
\begin{aligned}
0 & =\mu_{l, i} l_{i}^{-1} U_{i}-\lambda_{i}(1-\tau) w \\
\lambda_{i}(1-\tau) w l_{i} & =\mu_{l, i} U_{i}
\end{aligned}
$$


and the first order condition for consumption of other goods becomes:

$$
\begin{aligned}
0 & =\mu_{k=O, i} C_{k=O, i}^{I}{ }^{-1} U_{i}-\lambda_{i} P_{k=O} \\
\lambda_{i} P_{k=O} C_{k=O, i}^{I} & =\mu_{k=O, i} U_{i}
\end{aligned}
$$

Adding these together, $\lambda_{i}$ is given by:

$$
\begin{aligned}
U_{i}\left(\mu_{H, i}+\mu_{l, i}+\mu_{k=O, i}\right)=\lambda_{i}[ & P_{k=M} \xi_{i}{ }^{-1} H_{0, i}{ }^{1+\beta_{i}}+P_{k=M} C_{k=M, i}^{G} \\
& +P_{k=M} C_{k=M, i}^{I} \\
& \left.+(1-\tau) w l_{i}+P_{k=O} C_{k=O, i}^{I}\right]
\end{aligned}
$$

Without loss of generality, assume

$$
\mu_{H, i}+\mu_{k=O, i}+\mu_{l, i}=1
$$

Then

$$
\begin{aligned}
U_{i}=\lambda_{i}\left[P_{k=M} \xi_{i}{ }^{-1} H_{0, i}{ }^{1+\beta_{i}}+P_{k=M} C_{k=M, i}^{G}\right. & \\
& \left.\quad+\sum_{i} P_{k} C_{k, i}^{I}+(1-\tau) w\left(1-L_{i}\right)\right] \\
= & \lambda_{i}\left[(1-\tau) w+P_{k=M}\left(C_{k=M, i}^{G}+\xi_{i}{ }^{-1} H_{0, i}{ }^{1+\beta_{i}}\right)\right] \\
\lambda_{i}= & U_{i}\left[(1-\tau) w+P_{k=M}\left(C_{k=M, i}^{G}+\xi_{i}{ }^{-1} H_{0, i}{ }^{1+\beta_{i}}\right)\right]^{-1}
\end{aligned}
$$


Eliminating $\lambda_{i}$ from the first order conditions, the health first order condition becomes:

$$
\begin{aligned}
\mu_{H, i} U_{i}= & U_{i}\left[(1-\tau) w+P_{k=M}\left(C_{k=M, i}^{G}+\xi_{i}{ }^{-1} H_{0, i}{ }^{1+\beta_{i}}\right)\right]^{-1} \\
& \times\left[P_{k=M} \xi_{i}{ }^{-1} H_{0, i}{ }^{1+\beta_{i}}+P_{k=M} C_{k=M, i}^{G}+P_{k=M} C_{k=M, i}^{I}\right] \\
\mu_{H, i}\left[(1-\tau) w+P_{k=M}\left(C_{k=M, i}^{G}+\xi_{i}{ }^{-1} H_{0, i}{ }^{1+\beta_{i}}\right)\right] & \\
= & P_{k=M} \xi_{i}{ }^{-1} H_{0, i}{ }^{1+\beta_{i}}+P_{k=M} C_{k=M, i}^{G}+P_{k=M} C_{k=M, i}^{I} \\
P_{k=M} C_{k=M, i}^{I}= & \mu_{H, i}(1-\tau) w+\mu_{H, i} P_{k=M}\left(C_{k=M, i}^{G}+\xi_{i}{ }^{-1} H_{0, i}{ }^{1+\beta_{i}}\right) \\
& -P_{k=M} \xi_{i}{ }^{-1} H_{0, i}{ }^{1+\beta_{i}}-P_{k=M} C_{k=M, i}^{G} \\
= & \mu_{H, i}(1-\tau) w-\left(1-\mu_{H, i}\right) P_{k=M}\left(C_{k=M, i}^{G}+\xi_{i}{ }^{-1} H_{0, i}{ }^{1+\beta_{i}}\right) \\
C_{k=M, i}^{I}= & \mu_{H, i}(1-\tau) w P_{k=M}{ }^{-1}-\left(1-\mu_{H, i}\right)\left(C_{k=M, i}^{G}+\xi_{i}{ }^{-1} H_{0, i}{ }^{1+\beta_{i}}\right)
\end{aligned}
$$

The leisure first order condition becomes:

$$
\begin{aligned}
\mu_{l, i} U_{i} & =\frac{(1-\tau) w l_{i} U_{i}}{(1-\tau) w+P_{k=M}\left(C_{k=M, i}^{G}+\xi_{i}{ }^{-1} H_{0, i}{ }^{1+\beta_{i}}\right)} \\
(1-\tau) w l_{i} & =\mu_{l, i}\left[(1-\tau) w+P_{k=M}\left(C_{k=M, i}^{G}+\xi_{i}{ }^{-1} H_{0, i}{ }^{1+\beta_{i}}\right)\right] \\
l_{i} & =\mu_{l, i}\left[1+\frac{P_{k=M}}{(1-\tau) w}\left(C_{k=M, i}^{G}+\xi_{i}{ }^{-1} H_{0, i}{ }^{1+\beta_{i}}\right)\right]
\end{aligned}
$$


and the consumption first order condition becomes:

$$
\begin{aligned}
\mu_{k=O, i} U_{i} & =P_{k=O} C_{k=O, i}^{I} U_{i}\left[(1-\tau) w+P_{k=M}\left(C_{k=M, i}^{G}+\xi_{i}{ }^{-1} H_{0, i}{ }^{1+\beta_{i}}\right)\right]^{-1} \\
\mu_{k=O, i} & =P_{k=O} C_{k=O, i}^{I}\left[(1-\tau) w+P_{k=M}\left(C_{k=M, i}^{G}+\xi_{i}{ }^{-1} H_{0, i}{ }^{1+\beta_{i}}\right)\right]^{-1} \\
C_{k=O, i}^{I} & =\mu_{k=O, i} P_{k=O}{ }^{-1}\left[(1-\tau) w+P_{k=M}\left(C_{k=M, i}^{G}+\xi_{i}{ }^{-1} H_{0, i}{ }^{1+\beta_{i}}\right)\right] \\
& =\mu_{k=O, i}(1-\tau) w P_{k=O}{ }^{-1}\left[1+\frac{P_{k=M}}{(1-\tau) w}\left(C_{k=M, i}^{G}+\xi_{i}{ }^{-1} H_{0, i}{ }^{1+\beta_{i}}\right)\right]
\end{aligned}
$$

\section{B.3 Maximise Profits}

Firm profits are given by:

$$
\begin{aligned}
\pi_{k} & =P_{k} Q_{k}-w \sum_{i} L_{k, i} \\
& =P_{k} A_{k} L_{k}-w \sum_{i} L_{k, i} \\
& =P_{k} A_{k} \sum_{i} H_{i} L_{k, i}-w \sum_{i} L_{k, i}
\end{aligned}
$$

Maximising profits:

$$
\begin{aligned}
0 & =\frac{\partial \pi_{k}}{\partial L_{k, i}} \\
& =P_{k} A_{k} H_{i}-w \\
0 & =P_{k} A_{k} H_{i} L_{k, i}-w L_{k, i} \\
0 & =P_{k} A_{k} \sum_{i} H_{i} L_{k, i}-w \sum_{i} L_{k, i}
\end{aligned}
$$


Profits are therefore zero and so the perfect competition constraint gives:

$$
P_{k} Q_{k}=w \sum_{i} L_{k, i}
$$

Summing over all goods, wages are given by:

$$
\begin{aligned}
\sum_{k} P_{k} Q_{k} & =w \sum_{k} \sum_{i} L_{k, i} \\
& =w \sum_{i} L_{i} \\
w & =\frac{\sum_{k} P_{k} Q_{k}}{\sum_{i} L_{i}}
\end{aligned}
$$

\section{B.4 Government Provision of Healthcare}

To optimise how the government distributes healthcare, maximise the social welfare function subject to the government's budget constraint, using the Lagrangian method. The Lagrangian will be given by:

$$
\mathcal{L}=W+\lambda_{G}\left(P_{k=M} \sum_{i} C_{k=M, i}^{G}-\tau w \sum_{i} L_{i}\right)
$$

and the first order conditions by

$$
\begin{aligned}
0 & =\frac{\partial \mathcal{L}}{\partial H_{i}} \\
& =\frac{\partial W}{\partial H_{i}}+\lambda_{G} P_{k=M} \frac{\partial C_{k=M, i}^{G}}{\partial H_{i}}
\end{aligned}
$$


Healthcare purchased by government for individuals is given by:

$$
\begin{aligned}
H_{i}= & H_{S}{ }^{\gamma_{i}}\left(H_{0, i}+\xi_{i} H_{0, i}{ }^{-\beta_{i}}\left(C_{k=M, i}^{G}+C_{k=M, i}^{I}\right)\right) \\
C_{k=M, i}^{G}= & \frac{H_{i}-H_{S}{ }^{\gamma_{i}}\left(H_{0, i}+\xi_{i} H_{0, i}{ }^{-\beta_{i}} C_{k=M, i}^{I}\right)}{H_{S}{ }^{\gamma_{i}} \xi_{i} H_{0, i}{ }^{-\beta_{i}}} \\
= & H_{i}\left(H_{S}{ }^{\gamma_{i}} \xi_{i} H_{0, i}{ }^{-\beta_{i}}\right)^{-1} \\
& -\left(\xi_{i} H_{0, i}{ }^{-\beta_{i}}\right)^{-1}\left(H_{0, i}+\xi_{i} H_{0, i}{ }^{-\beta_{i}}\left(\mu_{H, i}(1-\tau) w P_{k=M}{ }^{-1}\right.\right. \\
& \left.\left.\quad-\left(1-\mu_{H, i}\right)\left(C_{k=M, i}^{G}+\xi_{i}{ }^{-1} H_{0, i}{ }^{1+\beta_{i}}\right)\right)\right) \\
= & \xi_{i}{ }^{-1} H_{0, i}{ }^{\beta_{i}} H_{S}{ }^{-\gamma_{i}} H_{i}-\xi_{i}{ }^{-1} H_{0, i}{ }^{1+\beta_{i}}-\mu_{H, i}(1-\tau) w P_{k=M}{ }^{-1} \\
& +\left(1-\mu_{H, i}\right)\left(C_{k=M, i}^{G}+\xi_{i}{ }^{-1} H_{0, i}{ }^{1+\beta_{i}}\right) \\
\mu_{H, i} C_{k=M, i}^{G}= & \xi_{i}{ }^{-1} H_{0, i}{ }^{\beta_{i}} H_{S}{ }^{-\gamma_{i}} H_{i}-\mu_{H, i} \xi_{i}{ }^{-1} H_{0, i}{ }^{1+\beta_{i}}-\mu_{H, i}(1-\tau) w P_{k=M}{ }^{-1} \\
C_{k=M, i}^{G}= & \xi_{i}{ }^{-1} H_{0, i}{ }^{\beta_{i}} H_{S}{ }^{-\gamma_{i}}\left(\mu_{H, i}{ }^{-1} H_{i}-H_{0, i} H_{S}{ }^{\gamma_{i}}\right)-(1-\tau) w P_{k=M}{ }^{-1}
\end{aligned}
$$

and so

$$
\begin{aligned}
\frac{\partial C_{k=M, i}^{G}}{\partial H_{i}} & =\mu_{H, i}{ }^{-1} \xi_{i}{ }^{-1} H_{0, i}{ }^{\beta_{i}} H_{S}{ }^{-\gamma_{i}} \\
& =H_{i}{ }^{-1}\left(C_{k=M, i}^{G}+\xi_{i}{ }^{-1} H_{0, i}{ }^{1+\beta_{i}}+(1-\tau) w P_{k=M}{ }^{-1}\right)
\end{aligned}
$$

Thus, the first order conditions are given by:

$$
\begin{aligned}
& 0=\frac{\partial W}{\partial H_{i}}+\lambda_{G} P_{k=M} H_{i}^{-1}\left(C_{k=M, i}^{G}+\xi_{i}{ }^{-1} H_{0, i}{ }^{1+\beta_{i}}+(1-\tau) w P_{k=M}{ }^{-1}\right) \\
& 0=P_{k=M}{ }^{-1} H_{i} \frac{\partial W}{\partial H_{i}}+\lambda_{G}\left(C_{k=M, i}^{G}+\xi_{i}{ }^{-1} H_{0, i}{ }^{1+\beta_{i}}+(1-\tau) w P_{k=M}{ }^{-1}\right)
\end{aligned}
$$




\section{B.4.1 Maximise Utility Welfare}

Social welfare from utility is given by

$$
W_{U}=\frac{1}{1-\nu} \sum_{i}\left[U_{i}^{1-\nu}-1\right]
$$

and so

$$
\frac{\partial W_{U}}{\partial H_{i}}=U_{i}^{-\nu} \frac{\partial U_{i}}{\partial H_{i}}
$$

Since utility is given by:

$$
U_{i}=H_{i}{ }^{\mu_{H, i}} l_{i}{ }^{\mu_{l, i}} C_{k=O, i}{ }^{\mu_{k=O, i}}
$$

then

$$
\begin{aligned}
\frac{\partial U_{i}}{\partial H_{i}} & =\mu_{H, i} H_{i}{ }^{\mu_{H, i}-1} l_{i}{ }^{{ }_{l, i}} C_{k=O, i}{ }^{\mu_{k=O, i}} \\
& =\mu_{H, i} H_{i}{ }^{-1} U_{i}
\end{aligned}
$$

and so

$$
\frac{\partial W_{U}}{\partial H_{i}}=\mu_{H, i} U_{i}^{1-\nu} H_{i}^{-1}
$$


The first order conditions are then

$$
\begin{aligned}
0= & P_{k=M}{ }^{-1} H_{i} \mu_{H, i} U_{i}{ }^{1-\nu} H_{i}{ }^{-1} \\
& +\lambda_{G}\left(C_{k=M, i}^{G}+\xi_{i}{ }^{-1} H_{0, i}{ }^{1+\beta_{i}}+(1-\tau) w P_{k=M}{ }^{-1}\right) \\
0= & \mu_{H, i} U_{i}{ }^{1-\nu} P_{k=M}{ }^{-1} \\
& +\lambda_{G}\left(C_{k=M, i}^{G}+\xi_{i}{ }^{-1} H_{0, i}{ }^{1+\beta_{i}}+(1-\tau) w P_{k=M}{ }^{-1}\right)
\end{aligned}
$$

Sum over $i$ to find $\lambda_{G}$ :

$$
\begin{aligned}
0= & P_{k=M}{ }^{-1} \sum_{i} \mu_{H, i} U_{i}{ }^{1-\nu} \\
& +\lambda_{G}\left(\sum_{i} C_{k=M, i}^{G}+\sum_{i} \xi_{i}{ }^{-1} H_{0, i}{ }^{1+\beta_{i}}+\sum_{i}(1-\tau) w P_{k=M}{ }^{-1}\right) \\
\lambda_{G}= & -P_{k=M}{ }^{-1} \sum_{i} \mu_{H, i} U_{i}{ }^{1-\nu} \\
& \times\left(C_{k=M}^{G}+\sum_{i} \xi_{i}{ }^{-1} H_{0, i}{ }^{1+\beta_{i}}+(1-\tau) n w P_{k=M}{ }^{-1}\right)^{-1}
\end{aligned}
$$


and so

$$
\begin{aligned}
0= & \mu_{H, i} U_{i}{ }^{1-\nu} P_{k=M}{ }^{-1} \\
& -P_{k=M}{ }^{-1} \sum_{i} \mu_{H, i} U_{i}{ }^{1-\nu} \\
& \times\left(C_{k=M}^{G}+\sum_{i} \xi_{i}{ }^{-1} H_{0, i}{ }^{1+\beta_{i}}+(1-\tau) n w P_{k=M}{ }^{-1}\right)^{-1} \\
& \times\left(C_{k=M, i}^{G}+\xi_{i}{ }^{-1} H_{0, i}{ }^{1+\beta_{i}}+(1-\tau) w P_{k=M}{ }^{-1}\right) \\
0= & \mu_{H, i} U_{i}{ }^{1-\nu}\left(C_{k=M}^{G}+\sum_{i} \xi_{i}{ }^{-1} H_{0, i}{ }^{1+\beta_{i}}+(1-\tau) n w P_{k=M}{ }^{-1}\right) \\
& -\sum_{i} \mu_{H, i} U_{i}{ }^{1-\nu}\left(C_{k=M, i}^{G}+\xi_{i}{ }^{-1} H_{0, i}{ }^{1+\beta_{i}}+(1-\tau) w P_{k=M}{ }^{-1}\right) \\
C_{k=M, i}^{G}= & \frac{\mu_{H, i} U_{i}{ }^{1-\nu}}{\sum_{i} \mu_{H, i} U_{i}{ }^{1-\nu}}\left(C_{k=M}^{G}+\sum_{i} \xi_{i}{ }^{-1} H_{0, i}{ }^{1+\beta_{i}}+(1-\tau) n w P_{k=M}{ }^{-1}\right) \\
& -(1-\tau) w P_{k=M}{ }^{-1}-\xi_{i}{ }^{-1} H_{0, i}{ }^{1+\beta_{i}}
\end{aligned}
$$

\section{B.4.2 Maximise Health Welfare}

Social welfare from health is given by

$$
W_{H}=\frac{1}{1-\nu} \sum_{i}\left[H_{i}{ }^{1-\nu}-1\right]
$$

and so

$$
\frac{\partial W_{H}}{\partial H_{i}}=H_{i}^{-\nu}
$$


The first order conditions are then

$$
\begin{aligned}
0= & P_{k=M}{ }^{-1} H_{i} H_{i}{ }^{-\nu} \\
& +\lambda_{G}\left(C_{k=M, i}^{G}+\xi_{i}{ }^{-1} H_{0, i}{ }^{1+\beta_{i}}+(1-\tau) w P_{k=M}{ }^{-1}\right) \\
0= & H_{i}{ }^{1-\nu} P_{k=M}{ }^{-1} \\
& +\lambda_{G}\left(C_{k=M, i}^{G}+\xi_{i}{ }^{-1} H_{0, i}{ }^{1+\beta_{i}}+(1-\tau) w P_{k=M^{-1}}\right)
\end{aligned}
$$

Sum over $i$ to find $\lambda_{G}$ :

$$
\begin{aligned}
0= & P_{k=M}{ }^{-1} \sum_{i} H_{i}{ }^{1-\nu} \\
& +\lambda_{G}\left(\sum_{i} C_{k=M, i}^{G}+\sum_{i} \xi_{i}{ }^{-1} H_{0, i}{ }^{1+\beta_{i}}+\sum_{i}(1-\tau) w P_{k=M}{ }^{-1}\right) \\
\lambda_{G}= & -P_{k=M}{ }^{-1} \sum_{i} H_{i}{ }^{1-\nu} \\
& \times\left(C_{k=M}^{G}+\sum_{i} \xi_{i}{ }^{-1} H_{0, i}{ }^{1+\beta_{i}}+(1-\tau) n w P_{k=M}{ }^{-1}\right)^{-1}
\end{aligned}
$$


and so

$$
\begin{aligned}
& 0=H_{i}^{1-\nu} P_{k=M}{ }^{-1} \\
& -P_{k=M}{ }^{-1} \sum_{i} H_{i}^{1-\nu} \\
& \times\left(C_{k=M}^{G}+\sum_{i} \xi_{i}{ }^{-1} H_{0, i}{ }^{1+\beta_{i}}+(1-\tau) n w P_{k=M}{ }^{-1}\right)^{-1} \\
& \times\left(C_{k=M, i}^{G}+\xi_{i}{ }^{-1} H_{0, i}{ }^{1+\beta_{i}}+(1-\tau) w P_{k=M^{-1}}\right) \\
& 0=H_{i}{ }^{1-\nu}\left(C_{k=M}^{G}+\sum_{i} \xi_{i}{ }^{-1} H_{0, i}{ }^{1+\beta_{i}}+(1-\tau) n w P_{k=M}{ }^{-1}\right) \\
& -\left(C_{k=M, i}^{G}+\xi_{i}^{-1} H_{0, i}{ }^{1+\beta_{i}}+(1-\tau) w P_{k=M}{ }^{-1}\right) \sum_{i} H_{i}{ }^{1-\nu} \\
& C_{k=M, i}^{G}=\frac{H_{i}{ }^{1-\nu}}{\sum_{i} H_{i}{ }^{1-\nu}}\left(C_{k=M}^{G}+\sum_{i} \xi_{i}{ }^{-1} H_{0, i}{ }^{1+\beta_{i}}+(1-\tau) n w P_{k=M}{ }^{-1}\right) \\
& -(1-\tau) w P_{k=M}{ }^{-1}-\xi_{i}{ }^{-1} H_{0, i}{ }^{1+\beta_{i}}
\end{aligned}
$$

\section{B.4.3 Maximise Income Welfare}

Social welfare from income is given by

$$
\begin{aligned}
W_{Y} & =\frac{1}{1-\nu} \sum_{i}\left[Y_{i}^{1-\nu}-1\right] \\
& =\frac{1}{1-\nu} \sum_{i}\left[\left(\sum_{k} P_{k} C_{k, i}^{I}\right)^{1-\nu}-1\right]
\end{aligned}
$$


and so

$$
\begin{aligned}
\frac{\partial W_{Y}}{\partial H_{i}} & =\left(\sum_{k} P_{k} C_{k, i}^{I}\right)^{-\nu} P_{k=M} \frac{\partial C_{k=M, i}^{I}}{\partial H_{i}} \\
& =\left(\sum_{k} P_{k} C_{k, i}^{I}\right)^{-\nu} P_{k=M}\left(H_{S}^{\gamma_{i}} \xi_{i} H_{0, i}{ }^{-\beta_{i}}\right)^{-1} \\
& =Y_{i}^{-\nu} P_{k=M}\left(H_{S}^{\gamma_{i}} \xi_{i} H_{0, i}^{-\beta_{i}}\right)^{-1}
\end{aligned}
$$

The first order conditions are then

$$
\begin{aligned}
0= & P_{k=M}{ }^{-1} H_{i} Y_{i}{ }^{-\nu} P_{k=M}\left(H_{S}{ }^{\gamma_{i}} \xi_{i} H_{0, i}{ }^{-\beta_{i}}\right)^{-1} \\
& +\lambda_{G}\left(C_{k=M, i}^{G}+\xi_{i}{ }^{-1} H_{0, i}{ }^{1+\beta_{i}}+(1-\tau) w P_{k=M}{ }^{-1}\right) \\
0= & H_{i} Y_{i}{ }^{-\nu}\left(H_{S}{ }^{\gamma_{i}} \xi_{i} H_{0, i}{ }^{-\beta_{i}}\right)^{-1} \\
& +\lambda_{G}\left(C_{k=M, i}^{G}+\xi_{i}{ }^{-1} H_{0, i}{ }^{1+\beta_{i}}+(1-\tau) w P_{k=M^{-1}}\right)
\end{aligned}
$$

Sum over $i$ to find $\lambda_{G}$ :

$$
\begin{aligned}
0= & \sum_{i} H_{i} Y_{i}^{-\nu}\left(H_{S}{ }^{\gamma_{i}} \xi_{i} H_{0, i}{ }^{-\beta_{i}}\right)^{-1} \\
& +\lambda_{G}\left(\sum_{i} C_{k=M, i}^{G}+\sum_{i} \xi_{i}^{-1} H_{0, i}{ }^{1+\beta_{i}}+\sum_{i}(1-\tau) w P_{k=M^{-1}}\right) \\
\lambda_{G}= & -\sum_{i} H_{i} Y_{i}^{-\nu}\left(H_{S}{ }^{\gamma_{i}} \xi_{i} H_{0, i}{ }^{-\beta_{i}}\right)^{-1} \\
& \times\left(C_{k=M}^{G}+\sum_{i} \xi_{i}{ }^{-1} H_{0, i}{ }^{1+\beta_{i}}+(1-\tau) n w P_{k=M}{ }^{-1}\right)^{-1}
\end{aligned}
$$


and so

$$
\begin{aligned}
& 0=H_{i} Y_{i}^{-\nu}\left(H_{S}{ }^{\gamma_{i}} \xi_{i} H_{0, i}{ }^{-\beta_{i}}\right)^{-1} \\
& -\sum_{i} H_{i} Y_{i}^{-\nu}\left(H_{S}^{\gamma_{i}} \xi_{i} H_{0, i}{ }^{-\beta_{i}}\right)^{-1} \\
& \times\left(C_{k=M}^{G}+\sum_{i} \xi_{i}{ }^{-1} H_{0, i}{ }^{1+\beta_{i}}+(1-\tau) n w P_{k=M}{ }^{-1}\right)^{-1} \\
& \times\left(C_{k=M, i}^{G}+\xi_{i}{ }^{-1} H_{0, i}{ }^{1+\beta_{i}}+(1-\tau) w P_{k=M}{ }^{-1}\right) \\
& 0=H_{i} Y_{i}^{-\nu}\left(H_{S}^{\gamma_{i}} \xi_{i} H_{0, i}{ }^{-\beta_{i}}\right)^{-1} \\
& \times\left(C_{k=M}^{G}+\sum_{i} \xi_{i}{ }^{-1} H_{0, i}{ }^{1+\beta_{i}}+(1-\tau) n w P_{k=M}{ }^{-1}\right) \\
& -\sum_{i} H_{i} Y_{i}^{-\nu}\left(H_{S}{ }^{\gamma_{i}} \xi_{i} H_{0, i}{ }^{-\beta_{i}}\right)^{-1} \\
& \times\left(C_{k=M, i}^{G}+\xi_{i}{ }^{-1} H_{0, i}{ }^{1+\beta_{i}}+(1-\tau) w P_{k=M}{ }^{-1}\right) \\
& C_{k=M, i}^{G}=\frac{H_{i} Y_{i}^{-\nu}\left(H_{S}^{\gamma_{i}} \xi_{i} H_{0, i}{ }^{-\beta_{i}}\right)^{-1}}{\sum_{i} H_{i} Y_{i}^{-\nu}\left(H_{S}^{\gamma_{i}} \xi_{i} H_{0, i}^{-\beta_{i}}\right)^{-1}} \\
& \times\left(C_{k=M}^{G}+\sum_{i} \xi_{i}{ }^{-1} H_{0, i}{ }^{1+\beta_{i}}+(1-\tau) n w P_{k=M}{ }^{-1}\right) \\
& -(1-\tau) w P_{k=M}{ }^{-1}-\xi_{i}{ }^{-1} H_{0, i}{ }^{1+\beta_{i}}
\end{aligned}
$$




\section{B.4.4 Maximise GDP}

GDP is given by

$$
\begin{aligned}
W_{G D P} & =\sum_{k} P_{k} Q_{k} \\
& =\sum_{k} P_{k} A_{k} L_{k} \\
& =\sum_{k} P_{k} A_{k} \sum_{i} H_{i} L_{k, i}
\end{aligned}
$$

and so

$$
\begin{aligned}
\frac{\partial W_{G D P}}{\partial H_{i}} & =\sum_{k} P_{k} A_{k} L_{k, i} \\
& =\sum_{k} P_{k} A_{k} L_{k} L_{i}\left(\sum_{i} H_{i} L_{i}\right)^{-1} \\
& =L_{i}\left(\sum_{i} H_{i} L_{i}\right)^{-1} \sum_{k} P_{k} A_{k} L_{k} \\
& =L_{i}\left(\sum_{i} H_{i} L_{i}\right)^{-1} W_{G D P}
\end{aligned}
$$

The first order conditions are then

$$
\begin{aligned}
0= & P_{k=M}{ }^{-1} H_{i} L_{i}\left(\sum_{i} H_{i} L_{i}\right)^{-1} W_{G D P} \\
& +\lambda_{G}\left(C_{k=M, i}^{G}+\xi_{i}{ }^{-1} H_{0, i}{ }^{1+\beta_{i}}+(1-\tau) w P_{k=M}{ }^{-1}\right)
\end{aligned}
$$


Sum over $i$ to find $\lambda_{G}$ :

$$
\begin{aligned}
0= & P_{k=M}{ }^{-1}\left(\sum_{i} H_{i} L_{i}\right)^{-1} W_{G D P} \sum_{i} H_{i} L_{i} \\
& +\lambda_{G}\left(\sum_{i} C_{k=M, i}^{G}+\sum_{i} \xi_{i}{ }^{-1} H_{0, i}{ }^{1+\beta_{i}}+\sum_{i}(1-\tau) w P_{k=M}{ }^{-1}\right) \\
= & P_{k=M}{ }^{-1} W_{G D P}+\lambda_{G}\left(C_{k=M}^{G}+\sum_{i} \xi_{i}{ }^{-1} H_{0, i}{ }^{1+\beta_{i}}+(1-\tau) n w P_{k=M}{ }^{-1}\right) \\
\lambda_{G}= & -P_{k=M}{ }^{-1} W_{G D P}\left(C_{k=M}^{G}+\sum_{i} \xi_{i}{ }^{-1} H_{0, i}{ }^{1+\beta_{i}}+(1-\tau) n w P_{k=M}{ }^{-1}\right)^{-1}
\end{aligned}
$$

and so

$$
\begin{aligned}
0= & P_{k=M}{ }^{-1} H_{i} L_{i}\left(\sum_{i} H_{i} L_{i}\right)^{-1} W_{G D P} \\
& -P_{k=M}{ }^{-1} W_{G D P}\left(C_{k=M}^{G}+\sum_{i} \xi_{i}{ }^{-1} H_{0, i}{ }^{1+\beta_{i}}+(1-\tau) n w P_{k=M}{ }^{-1}\right)^{-1} \\
& \times\left(C_{k=M, i}^{G}+\xi_{i}{ }^{-1} H_{0, i}{ }^{1+\beta_{i}}+(1-\tau) w P_{k=M}{ }^{-1}\right) \\
0 & H_{i} L_{i}\left(\sum_{i} H_{i} L_{i}\right)^{-1}\left(C_{k=M}^{G}+\sum_{i} \xi_{i}{ }^{-1} H_{0, i}{ }^{1+\beta_{i}}+(1-\tau) n w P_{k=M}{ }^{-1}\right) \\
& -C_{k=M, i}^{G}-\xi_{i}{ }^{-1} H_{0, i}{ }^{1+\beta_{i}}-(1-\tau) w P_{k=M}{ }^{-1}{ }^{G}{ }^{G}= \\
& H_{i} L_{i}\left(C_{k=M}^{G}+\sum_{i} \xi_{i}{ }^{-1} H_{0, i}{ }^{1+\beta_{i}}+(1-\tau) n w P_{k=M}{ }^{-1}\right) \\
& -(1-\tau) w P_{k=M}{ }^{-1}-\xi_{i}{ }^{-1} H_{0, i}{ }^{1+\beta_{i}}
\end{aligned}
$$




\section{B.4.5 Maximising Government Objectives}

In summary, if a government maximises an objective, government-provided healthcare will be distributed according to

$$
\begin{aligned}
C_{k=M, i}^{G}= & \rho_{i}\left(C_{k=M}^{G}+\sum_{i} \xi_{i}{ }^{-1} H_{0, i}{ }^{1+\beta_{i}}+(1-\tau) n w P_{k=M}{ }^{-1}\right) \\
& -(1-\tau) w P_{k=M}{ }^{-1}-\xi_{i}{ }^{-1} H_{0, i}{ }^{1+\beta_{i}}
\end{aligned}
$$

where

$$
\rho_{i}=\left\{\begin{array}{cc}
\frac{\mu_{H, i} U_{i}{ }^{1-\nu}}{\sum_{i} \mu_{H, i} U_{i}{ }^{1-\nu}} & \text { for the utility objective } \\
\frac{H_{i}{ }^{1-\nu}}{\sum_{i} H_{i}{ }^{1-\nu}} & \text { for the health objective } \\
\frac{H_{i} Y_{i}{ }^{-\nu}\left(H_{S} \gamma_{i} \xi_{i} H_{0, i}-\beta_{i}\right.}{\sum^{-1}} & \text { for the income objective } \\
\sum_{i} H_{i} Y_{i}{ }^{-\nu}\left(H_{S}{ }^{\gamma} \xi_{i} H_{0, i}{ }^{-\beta_{i}}\right)^{-1} & \\
\sum_{i} H_{i} L_{i} & \text { for the GDP objective }
\end{array}\right.
$$

and

$$
\sum_{i} \rho_{i}=1
$$


Using the government budget constraint,

$$
\begin{aligned}
& C_{k=M}^{G}=\tau w P_{k=M}{ }^{-1} \sum_{i} L_{i} \\
& =\tau w P_{k=M}{ }^{-1} \sum_{i}\left(1-\mu_{l, i}\left[1+\frac{P_{k=M}}{(1-\tau) w}\left(C_{k=M, i}^{G}+\xi_{i}{ }^{-1} H_{0, i}{ }^{1+\beta_{i}}\right)\right]\right) \\
& =\tau w P_{k=M}{ }^{-1} \sum_{i}\left(1-\mu_{l, i}\right) \\
& -\frac{\tau}{1-\tau} \sum_{i} \mu_{l, i}\left(C_{k=M, i}^{G}+\xi_{i}{ }^{-1} H_{0, i}{ }^{1+\beta_{i}}\right) \\
& =\tau w P_{k=M}{ }^{-1} \sum_{i}\left(1-\mu_{l, i}\right) \\
& -\frac{\tau}{1-\tau} \sum_{i} \mu_{l, i}\left(\rho_{i} C_{k=M}^{G}+\rho_{i} \sum_{i} \xi_{i}{ }^{-1} H_{0, i}{ }^{1+\beta_{i}}\right. \\
& \left.+\rho_{i}(1-\tau) n w P_{k=M}{ }^{-1}-(1-\tau) w P_{k=M}{ }^{-1}\right) \\
& =n \tau w P_{k=M}{ }^{-1}\left(1-\sum_{i} \mu_{l, i} \rho_{i}\right) \\
& -\frac{\tau}{1-\tau}\left(\sum_{i} \mu_{l, i} \rho_{i}\right)\left(C_{k=M}^{G}+\sum_{i} \xi_{i}{ }^{-1} H_{0, i}{ }^{1+\beta_{i}}\right) \\
& C_{k=M}^{G}\left(1+\frac{\tau}{1-\tau} \sum_{i} \mu_{l, i} \rho_{i}\right)=n \tau w P_{k=M}{ }^{-1}\left(1-\sum_{i} \mu_{l, i} \rho_{i}\right) \\
& -\frac{\tau}{1-\tau}\left(\sum_{i} \mu_{l, i} \rho_{i}\right) \sum_{i} \xi_{i}{ }^{-1} H_{0, i}{ }^{1+\beta_{i}}
\end{aligned}
$$




$$
\begin{aligned}
C_{k=M}^{G}= & \left(n \tau w P_{k=M}{ }^{-1}\left(1-\sum_{i} \mu_{l, i} \rho_{i}\right)\right. \\
& \left.-\frac{\tau}{1-\tau}\left(\sum_{i} \mu_{l, i} \rho_{i}\right) \sum_{i} \xi_{i}^{-1} H_{0, i}{ }^{1+\beta_{i}}\right) \\
& \times\left(1+\frac{\tau}{1-\tau} \sum_{i} \mu_{l, i} \rho_{i}\right)^{-1}
\end{aligned}
$$

\section{B.5 Solving the Model}

The price of healthcare goods is given by:

$$
\begin{aligned}
& \frac{P_{k=M} Q_{k=M}}{P_{k=O} Q_{k=O}}=\frac{\left(w \sum_{i} L_{i}\right)\left(\sum_{i} H_{i} L_{i}\right)^{-1} L_{k=M}}{\left(w \sum_{i} L_{i}\right)\left(\sum_{i} H_{i} L_{i}\right)^{-1} L_{k=O}} \\
& \frac{P_{k=M} A_{k=M} L_{k=M}}{P_{k=O} A_{k=O} L_{k=O}}=\frac{L_{k=M}}{L_{k=O}} \\
& \frac{P_{k=M} A_{k=M}}{P_{k=O} A_{k=O}}=1 \\
& P_{k=M}=\frac{P_{k=O} A_{k=O}}{A_{k=M}}
\end{aligned}
$$

